\title{
La investigación en historia militar de la Edad Moderna y sus fuentes. El Archivo General Militar de Segovia, decano de los Archivos Militares Españoles ${ }^{1}$
}

\author{
María Dolores Herrero Fernández-QuesadA \\ Universidad Complutense de Madrid \\ mariadhe@ghis.ucm.es
}

Recibido: 4 de octubre de 2012

Aceptado: 7 de mayo de 2013

\section{RESUMEN}

El presente artículo aúna dos objetivos. Por un lado, aproximarse brevemente a la nueva historiografía militar de la Edad Moderna y su vuelta a la reconsideración de fuentes primarias. Por otro lado, estudiar y analizar la documentación existente en el Archivo General Militar de Segovia, decano de los archivos históricos militares en España. El desarrollo de este segundo apartado incluye, primero, la historia, etapas de formación y organización de los fondos documentales del archivo. A continuación se considera el uso instrumental para la investigación histórica que dichos fondos permiten. Un uso múltiple dada la amplitud temática de las informaciones contenidas, que van desde lo personal (expedientes personales y matrimoniales, hojas de servicios, pasaportes, pleitos, testamentarías, etc.) a lo institucional (Montepío Militar, Justicia Militar).

Palabras clave: España siglos XVI-XVIII, historia militar, Archivos Militares, Archivo General Militar de Segovia, tipología documental militar.

\section{Sources and Research on Early Modern military history: The Archivo General Militar of Segovia, the oldest Spanish Military Archive}

\begin{abstract}
In this article, conceived from the perspective of the researcher, we start from a short introduction to the state of the art of Early Modern Military Historiography and the return to the primary sources. From this point we focus on the Archivo General Militar, Segovia, the oldest document repository of the Spanish Armies. As the oldest military archive, we make an approach to the documentation generated by the Army over the centuries and preserved in the Alcázar, to its specific document types, and to their use as instrument for the historical research. The analysis of these documentary resources is a valuable tool for research in Early Modern Spanish Military History.
\end{abstract}

Key words: military history, Spanish Centre of History and Military Culture, Military Archives, Segovia Military Archives, military document type, personnel records, marriage records, sheet services, military and heraldry passports, military charitable institution, lawsuits, military justice, executors (of a will).

1 Este artículo se inscribe en el marco del proyecto Mujer, liberalismo y espacio público en perspectiva comparada. (HAR2011-26344/HIST) financiado por el Ministerio de Educación. IP: Rosa Mª Capel Martínez. 


\section{INTRODUCCIÓN. EL INSTITUTO DE HISTORIA Y CULTURA MILITAR Y LOS ARCHIVOS MILITARES}

Cuando nuestros alumnos muestran preferencia por investigar la historia militar de la Edad Moderna, la primera pregunta -nada retórica, por cierto- es dónde hay que trabajar. Dónde están las fuentes documentales primarias para el estudio de los ejércitos modernos. Y es entonces cuando conocen y entran en contacto con el hoy Instituto de Historia y Cultura Militar.

El Instituto de Historia y Cultura Militar (IHCM) con sede en el antiguo Cuartel del Infante Don Juan, en el madrileño Paseo Moret, es hoy el organismo del que depende y que tiene competencias sobre todo el patrimonio histórico documental del Ejército de Tierra conservado en sus archivos -independientemente de su sede geográfica-, el bibliográfico -con importante fondo impreso histórico- y el museológico con notables Museos Militares entre los que cabe mencionar el recientemente inaugurado Museo del Ejército con sede en el Alcázar de Toledo. De esta forma, se mantiene en el siglo XXI la gestión autónoma de los archivos militares por parte del Ministerio de Defensa, independiente a la de la Administración del Estado.

Tras la supresión del antiguo Servicio Histórico Militar, creado en 1939, se fundó el IHCM en 1998 conceptualmente como heredero de aquella institución, pero con criterios renovados, de ahí que en la actualidad, de una de sus tres Subdirecciones, dependan los Archivos Generales Militares Españoles. Hasta ese año, solo existía con la denominación Archivo Genera Militar, el instalado en el Alcázar de Segovia desde 1898. Hasta la entrada en vigor del nuevo Reglamento de Archivos Militares de 1998, el de Madrid mantuvo la suya de origen como Archivo Central del Servicio Histórico Militar, pasando desde entonces a denominarse también Archivo General Militar de Madrid. Los otros dos centros que comparten la categoría de Archivos Generales en la actualidad son el de Guadalajara dedicado a la documentación relativa a la tropa desde $1967^{2}$, y el de más reciente formación en el histórico Palacio de Polentinos de Ávila (antigua sede de la extinta Academia de Intendencia) dedicado monográficamente a la Guerra Civil Española ${ }^{3}$.

De esta forma, constatamos que el primer Archivo General Militar fue fundado en 1898 con sede en la fortaleza segoviana, convirtiéndose en el decano de los archivos militares españoles que siguen gestionando los Ejércitos. Nuestra atención en este trabajo se centrará en el archivo segoviano, y será planteado desde la óptica del investigador, pues por experiencia propia, bien podemos afirmar que sus fondos documentales son una valiosa herramienta para la investigación en historia militar de la Edad Moderna española. Este instrumento partiendo de una breve aproximación al estado de la cuestión de la historiografía militar, lo dedicamos al Archivo General Militar de Segovia y sus fondos como centro documental de los ejércitos más antiguo. Como Decano de los archivos militares españoles, realizaremos una aproximación

\footnotetext{
2 López Jiménez, J.: “Las fuentes: los archivos militares”, Ayer, 57 (2005), pp. 27-49.

3 Sobre el Sistema de Archivos de Defensa en la actualidad, encontramos trabajos de interés en una publicación periódica del propio Ministerio, el Boletín Informativo del Sistema Archivístico de la Defensa. De la misma forma, también se editan artículos sobre los fondos militares que se encuentran en otros archivos históricos españoles.
} 
a la documentación generada por la institución militar durante siglos, su tipología documental específica, y su aplicación al estudio de la historia.

Finalizada la Guerra Civil en 1939, con dependencia orgánica del Estado Mayor del Ejército se creó el antiguo Servicio Histórico Militar en el edificio del Seminario de Nobles de Madrid, en la calla Mártires de Alcalá. Y dentro de la institución se dio prioridad a la formación de un Archivo Central reuniendo los fondos documentales del conocido como Depósito de la Guerra que se formó durante la Guerra de la Independencia, en 1810, con el fin de centralizar toda la documentación de las campañas, tanto de carácter histórico-militar, como geográfica y cartográfica. Junto a ello, se depositó la documentación generada en la recién finalizada Guerra Civil (llamado entonces "Archivo Histórico de la Campaña"), y otro importante fondo documental reunido por el ejército para la Comisión Histórica de las Campañas de Marruecos que fue articulada a partir de 1927 con la documentación de la presencia española en África. Y este fue el punto de partida del Archivo Central del Servicio Histórico Militar, hasta el Real Decreto de 4 de diciembre de 1998, disposición que recoge el nuevo Reglamento de Archivos Militares Españoles ${ }^{4}$, por el que a aquel ya se le reconoce como Archivo Nacional, de titularidad estatal, pasando a denominarse Archivo General Militar de Madrid (AGMM).

El objetivo primigenio de la concentración de estos yacimientos documentales era reunir, clasificar, investigar y estudiar sobre fuentes directas la historia militar de España, a través del sistema llamado de "Comisiones Militares" o "Ponencias" integradas por oficiales que finalmente trabajaron sobre la Guerra de la Independencia, las Guerras Carlistas, la Guerra de los Pirineos, las Campañas de Marruecos y la propia Guerra Civil Española, con una producción editorial desigual en cada una de ellas.

Los archivos militares y sus fuentes, son herramientas imprescindibles para la investigación en Historia Moderna, tanto el AGMS del que nos ocupamos en este artículo; como el AGMM, con un gran potencial documental y unas importantes $\mathrm{Co}$ lecciones Documentales de consulta obligada para el historiador, como se ha demostrado en los trabajos que se han editado en las últimas décadas, de los que trataremos en el epígrafe 2.

El contexto histórico del XX español y los prejuicios intelectuales derivados del mismo, han dilatado el proceso de acercamiento del historiador a los archivos militares, pero finalmente investigaciones y tesis doctorales en la mente de todos han pasado por trabajar y analizar la documentación militar como instrumento documental clave e imprescindible a la hora de hacer historia militar. Desde unos planteamientos metodológicos renovados había que volver a las fuentes primarias. En el marco historiográfico europeo, haremos especial mención a la historiografía militar de la Edad Moderna en las últimas décadas, producción historiográfica derivada de la consulta e investigación de la documentación militar.

4 Real Decreto 2598/1998 (de 4 de diciembre). 


\section{APROXIMACIÓN A LA HISTORIOGRAFÍA MILITAR. LA VUELTA A LAS FUENTES}

En los estudios históricos y en las últimas décadas, la investigación en Historia Militar ha sufrido un notable proceso de transformación, de tal forma que se puede hablar de una profunda renovación historiográfica tanto de contenidos como metodológica. En décadas anteriores, a la hora de abordar este tema desde la Universidad, los diferentes análisis han partido del acusado vacío de trabajos en España, citando siempre y en primer lugar las referencias extranjeras como modelo para después repasar la producción española en los últimos años, asi como señalando las vías de investigación por explorar a medio y largo plazo.

En el siglo XX, el siglo de las dos grandes guerras mundiales, asistimos a la renovación de los estudios de Historia Militar ${ }^{5}$. La historia de la guerra, de las batallas, conformó el modelo de historia militar desde la Antigüedad al Medievo, que pervivió también en la Edad Moderna, tanto por la trascendencia de la guerra en el marco de las Relaciones Internacionales como por la entrada en escena de los militares escritores, profesionales de las armas a quienes debemos desde finales del siglo XV la tratadística militar mas clásica que circuló por Europa, y cuyo legado impreso nos ha permitido conocer la estructura militar del momento, la capacidad de innovación de los ejércitos a través de la evolución de las técnicas armamentísticas y tácticas en boga, o las competencias, espacios de poder y funciones del militar profesional. ${ }^{6} \mathrm{~A}$ esta tendencia hay que sumar en las dos centurias siguientes la incorporación de tratadistas dedicados a la Marina por la importancia que lo naval adquirió en el arte militar y en especial en las relaciones internacionales. En el siglo ilustrado, se amplían las disciplinas que históricamente habían configurado la literatura militar, entre otras razones por la creciente tecnificación de las actividades bélicas que condicionaron la formación de los oficiales y la fundación de colegios militares para la instrucción de los profesionales de las armas, con una producción editorial propia que compendia el conocimiento facultativo más que relevante en el caso de la ingeniería militar, la artillería o la Armada. Como genuinos productos ilustrados, los tratados militares

5 Martínez Ruiz, E. y Pi Corrales, M. de P.: "La investigación en la historia militar moderna: realidades y perspectivas", Revista de Historia Militar, no extraordinario dedicado a Historia Militar: Métodos y recursos de investigación, Madrid, IHCM, (2002), pp. 123-169.

6 Para el conocimiento general de los tratadistas militares en la época vid. GonzÁlez CASTRILlo, R.: El arte militar en la España del siglo XVI, Madrid, 2000; así como el capítulo que dedica a la tratadística militar clásica David García Hernán en su artículo, vid. GARcía HERnán, D.: "Historiografía y fuentes para el estudio de la guerra y el ejército en la España del Antiguo Régimen”, en Revista de Historia Militar, n extraordinario dedicado a Historia Militar: Métodos y recursos de investigación. Madrid, IHCM, 2002. pp. 183-292; CAmpillo, A.: La fuerza de la razón. Guerra, estado y ciencia en los tratados militares del Renacimiento de Maquiavelo a Galileo. Murcia, 1986; García Hurtado, M.: Traduciendo la guerra. Influencias extranjeras y recepción de las obras militares francesas en la España del siglo XVIII, 1999; o EsPINO LóPEZ, A.: Guerra y cultura en la época moderna. La tratadística militar hispánica de los siglos XVI y XVII: libros, autores y lectores, Madrid, Ministerio de Defensa, 2001. Para la tratadística clásica sobre las disciplinas mas técnicas y de fuerte componente científico del arte militar, fortificación y artillería, vid. también HERRERo FERNÁNDEZQuesada, M. ${ }^{a}$ D.: Catálogo de la biblioteca del real Colegio de Artillería de Segovia. II. Fondos artilleros y de fortificación. Segovia, BCA,199; así como García Hourcade, J. L. y Valles Garrido, J. M.: Catálogo de la Biblioteca el Real Colegio de Artillería de Segovia. I. Fondos científicos, Segovia, BCA, 1989. 
dieciochescos ponen de manifiesto la voluntad de difundir la aplicación práctica de los conocimientos militares para la formación de los oficiales, siempre encontramos una vocación docente direccionada hacia los futuros compañeros de profesión.

En el siglo XIX se aprecia una continuidad en los planteamientos de la Historia Militar a pesar de la transformación conceptual de los ejércitos, ya nacionales, pero hasta entonces reales. La historiografía militar decimonónica se movía aún en unas coordenadas marcadas por la narración épica de las hazañas militares, hasta que el positivismo analizó las fuentes y documentó los relatos históricos. Como novedad, únicamente se sumó la aportación en el marco conceptual de relevantes teóricos de la guerra en la mente de todos como Jomini, Clausewitz, Almirante o Villamartín, pero lejos aún de la incorporación de otras perspectivas, enfoques y temas de la historia militar mas integral contemporánea.

Sin embargo, las guerras mundiales del XX propiciaron el debate sobre la guerra, el replanteamiento de los conflictos militares desde lo conceptual hasta lo mas técnico de la ciencia bélica, de tal manera que se ponen las bases de la Historia Militar, según la entendemos hoy, como el estudio de amplios procesos en el tiempo y enfatizando especialmente el análisis de las claves; y este proceso coincide en historiografía general con la renovación metodológica y de contenidos de la Escuela de los Annales. Esta tendencia historiográfica y la metodología de la investigación aplicada a la historia militar consolidó el divorcio anunciado entre el historiador profesional y el historiador militar, que seguía respondiendo al perfil del militar erudito que se ocupaba de investigar y/o publicar sobre la historia de los ejércitos, sin método pero con alma. Esto llevó a que la historia militar fuera considerada, como apuntan Martínez Ruiz y Pi Corrales, una actividad marginal, muy poco apreciada por los historiadores "a secas", es lo que otros autores como Andújar denominan la "vieja historia militar"7. $\mathrm{Y}$ este era el escueto escenario en el que se movieron las investigaciones hasta mas o menos 1970, en que la historiografía anglosajona realizó aportaciones y avances en los estudios sobre los ejércitos, teniendo como pionera, exponente y referente indiscutible, la obra ya clásica de Roberts sobre la Revolución Militar ${ }^{8}$.

Los estudios que implicaban y explicitaban el maridaje entre guerra y sociedad surgieron principalmente como reacción a la situación historiográfica anteriormente descrita en la que los trabajos sobre historia militar no analizaban los ejércitos de forma integral, sino su actividad, la guerra (o como mucho la orgánica que permitía hacer la guerra), enfatizándose siempre la denominada historia política del Ejército, en detrimento de la social de la institución militar. En suma, se circunscribían al hecho militar, a las batallas y, finalmente también, a lo que hoy entendemos por militaria, sin análisis de mayor magnitud, y siempre con planteamientos y desarrollos desde dentro de la institución militar, con curiosidad relatora pero sin distancia, y desde luego lejos todavía de interesarse por las relaciones de los ejércitos con la sociedad.

En efecto, la historiografía anglosajona fue pionera, y fueron los historiadores británicos y americanos quienes en las tres últimas décadas han incorporado al mundo

7 AndúJar Castillo, F.: "De la "nueva historia militar" a la historia vieja y "nueva historia militar", en Barros, C. (ed.): Historia a debate, La Coruña, 2000. 3 vol.

8 Roberts, M.: The Military Revolution, 1560-1660, Belfast, 1956. 
universitario los estudios sobre la guerra y la milicia en general, engarzados con el estudio de la sociedad, la economía, la política, la ciencia y la técnica9 ${ }^{9}$. Sería injusto personalizar aquí, pero si cabe señalar que entre las figuras más destacadas de la historiografía anglosajona dedicada al estudio de la historia militar, Howard ${ }^{10}$ ha sido considerado como el "hombre que rescató para las humanidades el estudio de la historia de la guerra y que, simultáneamente, dio vida a los estudios estratégicos como materia académica en el continente europeo" ". A partir de aquí, entre la producción historiográfica hay que destacar las obras, ya de referencia, de Parker, Thompson y Quatrefages, entre otros.

La historiografía francesa también se incorporará al proceso de renovación de la historiografía militar, marcando un antes y un después André Corvisier con la coordinación de un número monográfico de la Revue d'Histoire Moderne et Contemporaine $^{12}$, dedicado a los estudios de historia militar de los siglos XVII y XVIII, con un artículo suyo en el que reflexionaba sobre diversos aspectos de la historia militar al tiempo que ofrecía un repertorio de toda la bibliografía sobre el tema editada en Francia desde 1940, incluidas las tesis doctorales leídas en la Universidad ${ }^{13}$. Corvisier, además, es el autor de una obra definitiva para la historiografía militar, modelo y referente de muchos estudios posteriores, sobre el Ejército francés a finales del siglo XVII, y de gran repercusión en la historiografía española. ${ }^{14}$

Pero será en la década de los ochenta cuando se multiplique la producción editorial de la renovada historia militar, con nuevas perspectivas y más amplios enfoques que rebasan los antiguos límites de las crónicas de las guerras ${ }^{15}$, lo que coincidió en el tiempo con la aparición en el ámbito de la historia militar de historiadores civiles que aplicaron la metodología y planteamientos científicos a esta línea de investigación. Este aspecto ha sido decisivo para consolidar el convencimiento historiográfico generalizado desde entonces hasta hoy de que no puede haber historia general sin

9 Sería muy prolijo incluir aquÍ un repertorio, sin embargo son de cita obligada las obras de: PARKER, G.: La revolución militar. Las innovaciones militares y el apogeo de Occidente. 1500-1800. Barcelona, Crítica, 1990; McneIll, W. H.: La búsqueda del poder. Tecnología, fuerzas armadas y sociedad desde 1000 d. C., Madrid, Siglo XX, 1988; Hale, J. R.: Guerra y sociedad en la Europa del Renacimiento 1450-1620. Madrid, Ministerio de Defensa, 1990; Duffy, C.: The Military experience in the Age of Reason, Londres, 1987; Anderson, M. S.: Guerra y sociedad en la Europa del Antiguo Régimen. 1618-1789, Madrid, Ministerio de Defensa, 1989; Black, J.: The Cambridge Illustrated Atlas of Warfare: Renaissance to revolution. 14921792, Cambridge University Press, 1996; o por cerrar el capítulo de citas clásicas e imprescindibles hay que recordar aquí la edición en castellano de la Historia del Mundo Moderno de la Universidad de Cambridge que, publicada por Sopena, incluyó varios capítulos dedicados a "Las Fuerzas Armadas y el arte militar".

10 Howard, M.: La guerra en la historia europea, México, 1983.

11 Aspizua, J., Cachinero, J. y Jensen, G.: "la Historia militar: una carencia intelectual en España", en Fusi, J. P. (ed.): La historia en el 92, n 10 de la Revista Ayer, Madrid, Marcial Pons, 1993. pp. 63-76.

12 Corvisier, A. (coord.): "Etudes d'Histoire Militaire (XVIIe-XXe. Siècles)", número extraordinario de la Revue d'Histoire Moderne et Contemporaine, (tomo XX), enero-marzo de 1973.

13 En cuanto a la historiografía francesa ocupada en historia militar cabe citar aquí el trabajo de MARTEL, A.: "Le renouveau de l'histoire militaire en France", Revue Historique, 497 (enero-marzo 1971), pp. 107-126; así como el trabajo de Coutau-Begarie, H.: Le phenomene "nouvelle histoire". Strategie et ideologie des nouveaux historiens, Paris, 1983. pp. 183-187.

14 Corvisier, A.: L'Armée française de la fin du XVIIe siècle au Ministère de Choisel. Le soldat, París, 1964.

15 SaAvedra VÁzquez, Ma . C.: "De la Historia de las Batallas al impacto de la guerra: algunas consideraciones sobre la actual historiografía militar española”, Obradoiro de Historia Moderna, I (1992), pp. $207-221$. 
incorporar un tratamiento renovado de las actividades militares y bélicas del pasado y esto vale tanto para la guerra convencional como para la naval ${ }^{16}$.

De esta forma, y parafraseando a Geoffrey Best, también un clásico de la historiografía militar contemporánea, ya se había llegado al convencimiento de que "así como la guerra es un asunto demasiado serio para dejarlo en manos de los generales, así también la historia y el análisis científico de la guerra se consideraban conceptos demasiado serios como para ser confiados a militares y a entusiastas de la guerra..."17.

En este contexto, el debate sobre la historia militar y su renovación historiográfica, tanto de contenidos como metodológica, estaba servido. Y la respuesta la encontramos en el hecho de que la producción investigadora y editorial en los noventa fue en aumento, de tal manera que en las vanguardias historiográficas está mas que asumida la necesidad de la investigación en historia militar para -en opinión de García Cárcel-"completar de manera coherente y equilibrada la escritura de la Historia" 18. Para este historiador hoy ya no se plantea la antigua confrontación entre Marte y Minerva, sino -y siguiendo la estela historiográfica norteamericana- "la guerra frente a la cultura, la violencia frente a la paz, la espada frente a la pluma. La alternativa a esa dualidad tan contrapuesta en los últimos años es el retorno de Minerva: el uso inteligente de la correlación de fuerzas, la estrategia de la prudencia y del saber hacer ante el conflicto, la perfecta compatibilidad entre guerra y cultura".

Es una síntesis muy ajustada de las tendencias historiográficas actuales en historia militar, en las que partiendo de aquellos pioneros trabajos clásicos que maridaron la guerra y la sociedad en sus estudios, en este proceso de evolución hoy ya se analiza el maridaje entre guerra y cultura, se reflexiona sobre la cultura de la guerra sin mas prejuicios que los justos, abriendo el marco de las investigaciones a todos los ámbitos de repercusión sobre la sociedad civil de las actividades desarrolladas por los ejércitos, por los militares a lo largo de la historia, en diferentes escenarios como el científico, tecnológico, humanístico y cultural, histórico, periodístico, social, educacional, pedagógico, sanitario, artístico, museístico, etc ${ }^{19}$. Y, en todo este proceso de crecimiento historiográfico, se impone una cultura de la guerra, pero no de la de Marte, sino la de Minerva, analizando de forma integral en el marco de los grandes procesos históricos.

\subsection{HISTORIA MILITAR DE LA EDAD MODERNA}

En cuanto a la Historiografía militar moderna, en los últimos años se ha producido notablemente, y el análisis de la historia militar de todo el periodo moderno es una herramienta interpretativa de primer orden. En el caso español, hay que partir de las

\footnotetext{
16 Cepeda Gómez, J.: "La historiografía sobre la Marina en los siglos XVIII y XIX", Revista de Historia Naval, 56 (2008), pp. 123-146.

17 Best, G.: Guerra y sociedad en la Europa revolucionaria. 1770-1870, Madrid, Ministerio de Defensa, 1990.

18 García Cárcel, R. y Herrero Fernández-Quesada, M. a D.: "Historia militar. Las letras de las armas", en ABC Blanco y Negro CULTURAL (2004).

19 Herrero Fernández-Quesada, ibidem; Herrero Fernández-Quesada, M. a D.: Orígenes del Museo del Ejército. Aproximación histórica al primer Real Museo Militar español, Madrid, Ministerio de Defensa, 1996.
} 
clásicas grandes obras generales decimonónicas, los Barado ${ }^{20}$, Clonard $^{21}$, Almirante ${ }^{22}$ o Arántegui ${ }^{23}$, de tono descriptivo, en ningún caso analítico, que sin embargo aún hoy son un referente imprescindible como punto de partida de las investigaciones en historia militar por su aportación general a la orgánica y por su visión casi enciclopédica de las actuaciones militares de los ejércitos en la historia.

En nuestra historiografía militar más reciente, hay algunas obras generales (pocas aún) que son de cita obligada y han dado marco y contexto a los estudios monográficos y sectoriales en historia militar, como la editada en la década de los 80 Historia social de las fuerzas armadas ${ }^{24}$. De la misma forma, y al socaire del traslado del Museo del Ejército de Madrid a Toledo, el Ministerio de Defensa ha reunido a un buen número de especialistas en la publicación de una obra general, Aproximación a la Historia Militar de España ${ }^{25}$, aunque en ningún caso ha venido a llenar el vacío de una gran obra general de la historia militar de España, con criterios científicos y metodológicos renovados. Recientemente, han comenzado a salir publicados los primeros volúmenes de una Historia Militar de España, por iniciativa de la Academia de la Historia ${ }^{26}$.

En cuanto a las publicaciones planteadas como herramientas de consulta para el estudio de la historia de los ejércitos, siguiendo la línea de Almirante y después de Corvisier, Cristina Borreguero ha editado un instrumento para el estudio y comprensión de la historia militar, un Diccionario de Historia Militar ${ }^{27}$. De la misma forma, cabría señalar que por primera vez en una obra general como la Enciclopedia de Historia de España, dirigida por Miguel Artola, en los dos diccionarios, uno de biografías y otro de instituciones, el profesor Cepeda Gómez coordinó un equipo de historiadores militares que redactaron voces específicas de la institución militar. ${ }^{28}$ Otro diccionario no general, sino mas específico, pero valioso y clarificador fue el publicado por

20 Barado, F.: Museo militar. Historia del ejército español, armas, uniformes, sistemas de combate, instituciones, organización del mismo desde los tiempos mas remotos hasta nuestros días, Barcelona, 1884, 3 tomos; y Literatura militar española, Barcelona, 1890.

21 Clonard, C. de: Historia orgánica de las armas de Infantería y Caballería españolas, desde la creación del Ejército permanente hasta el día, Madrid, 1847; y Memoria histórica de las Escuelas Militares, 1847.

22 Almirante, J.: Diccionario militar, Etimológico, Histórico, Tecnológico, Madrid, Imp. y lit. del depósito de la Guerra, 1869; Bibliografía militar de España, Madrid, Imp. M. Tello. 1876; Bosquejo de la historia militar de España, Madrid, Imp. Sucesores de Rivadeneyra, 1923; y Estudios militares. Antología. Arte Militar, Historia, Bibliografia, Madrid, Ed. Ejército, 1943.

23 Arántegui y sanz, J.: Historia de la artillería española. Madrid, 1885.

24 VV.AA.: Historia social de las Fuerzas Armada, Madrid, Alhambra, 1986. 8 tomos.

25 VV.AA.: Aproximación a la historia militar de España. Madrid, Ministerio de Defensa, 2006. 3 vol.

26 La Academia de la Historia y la Comisión Española de Historia Militar han emprendido la colección Historia Militar de España, cuyo director es Hugo O’Donnell. Hasta la fecha han salido editados tres tomos., el primero dedicado a la prehistoria y la antigüedad, coordinado por Martín Almagro Gorbea; el segundo sobre la Edad Media, coordinado por Miguel A. Ladero Quesada; y un tercero, que es el primer volumen dedicado a la Edad Moderna; Historia Militar de España, Edad Moderna. I. Ultramar y la Marina, Madrid, 2012.

27 Borreguero Beltrán, C.: Diccionario de Historia Militar: Desde los reinos medievales hasta nuestros días, Barcelona, 2000.

28 Artola, M.: En la obra citada en el texto, nos referimos al Diccionario Biográfico, y al de Instituciones, tomos 5 y 6 respectivamente, Madrid, Alianza Editorial, 1993. Hasta entonces, y ante la necesidad de este tipo de herramientas, había que recurrir a la obra de Almirante y de otros militares del XX como LóPEZ MuÑIz, G.: Diccionario enciclopédico de la guerra, Madrid, 1954, o BordeJE, F.: Diccionario militar estratégico y político. Guía para el lector, Madrid, 1981. 
Mora-Figueroa, pero centrado en los términos del arte de la fortificación ${ }^{29}$, que tiene un precedente para los Cuerpos Facultativos en el diccionario que publicó Agar para voces relacionadas con la compleja ciencia artillera ${ }^{30}$. Aún esperamos mucho en un futuro no muy lejano de este tipo de herramientas auxiliares para el estudio de la historia militar.

Asimismo, cabe señalar aquí como instrumentos auxiliares para la investigación de la historia de los ejércitos las publicaciones que se han dedicado en los últimos años a las fuentes, los archivos y bibliotecas militares. La aproximación, conocimiento y difusión de la documentación como clave para la orientación y nuevos criterios de la investigación en historia militar. Por su parte, el Ministerio de Defensa publicó una escueta Guía de Archivos Militares que sirve simplemente para situarse en el mapa del sitio de los contenedores del patrimonio documental militar español. Sin embargo, para el Archivo General Militar de Segovia, ha sido una ayuda inestimable -aunque incompleto-su Catálogo de la primera sección que recoge los Expedientes Personales de los militares españoles ${ }^{31} ; \mathrm{y}$ desglosado de esta inmensa sección el mas reciente Catálogo de militares Célebres ${ }^{32}$, subsección muy consultada en este archivo, como veremos. De igual forma, resulta de gran utilidad el Catálogo que publicó Enrique de Ocerín sobre los Expedientes Matrimoniales de militares y marinos que se conservan también en aquel centro documental ${ }^{33}$. Con posterioridad, en el archivo segoviano se editaron a finales de la década de los 80 dos catálogos por el Coronel Borreguero, los de la segunda y tercera secciones; así como una publicación sobre fondos hemerográficos del archivo, de mayor interés para la investigación en historia contemporánea.

Para la investigación en el Archivo General Militar de Madrid, es imprescindible el Catálogo de la Colección del Fraile ${ }^{34}$ publicado en primera edición en los ochenta y recientemente editado de nuevo con motivo de la conmemoración del Bicentenario de la Guerra de la Independencia. De igual forma, y al socaire de este evento, nuestro equipo ha publicado con el Instituto de Historia y Cultura Militar, una investigación que reúne los fondos que sobre aquella guerra se conservaban dispersos entre la enorme Colección General de Documentos (CGD) del Archivo General Militar de Madrid ${ }^{35}$. Como continuación a este trabajo, se ha editado más recientemente el segundo volumen del proyecto de investigación que coordinamos, y que ofrece al investigador una herramienta para trabajar sobre los fondos que, también sobre esa

\footnotetext{
29 Mora-Figueroa, L.: Glosario de arquitectura defensiva medieval, Cádiz, 1994.

30 Agar, L.: Diccionario ilustrado de artillería. Madrid, 1853.

31 Índice de Expedientes Personales del Archivo General Militar, Madrid, CSIC, 1958.

32 Vázquez Gimeno, G.: Catálogo de Expedientes de Personas Célebres del Archivo General Militar de Segovia, Madrid, Ministerio de Defensa, 1999.

33 Ocerín Y García de Llamera, E. de: Índice de los Expedientes Matrimoniales de militares y marinos que se conservan en el Archivo General Militar (1761-1865), Madrid, CSIC-Instituto Jerónimo Zurita, 1959, 2 tomos.

34 Freire López, A. M. a : re los regimientos de Andalucía, Índice bibliográfico de la Colección Documental del Fraile, Madrid, SHM, 1983.

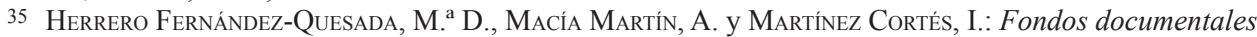
de la Guerra de la Independencia en la Colección General de Documentos y su Apéndice (Colección CárdenasMexía) del Archivo General Militar de Madrid, Madrid, Ministerio de defensa, 2008.
} 
misma guerra, se encuentran en otra de las grandes colecciones documentales del archivo, la Colección Blake. ${ }^{36}$

En cuanto a los instrumentos de consulta del patrimonio bibliográfico militar español, no hay una producción editorial relevante que nos acerque a los fondos, las bibliotecas históricas militares no cuentan con catálogos ni inventarios impresos de sus fondos así como tampoco ha sido frecuente que se consulten por los investigadores y universitarios puesto que se siguen conservando en instituciones militares. Sin embargo, aquí parece oportuno recordar una iniciativa aislada, el proyecto editorial Biblioteca de Ciencia y Artillería para la catalogación de los fondos de la Biblioteca de la Academia de Artillería de Segovia que se puso en marcha a finales de los 80 y que ha editado tres catálogos sobre sus fondos con criterios temáticos, el primero de fondos científicos, el segundo de obras de artillería y fortificación, y el último de fondos geográficos ${ }^{37}$. Sin embargo, no contamos con herramientas de consulta similares de otros centros del patrimonio bibliográfico militar, aunque en las biblioteca Militares como la de Madrid (IHCM) la consulta presencial permite acceder a los fondos a través de Intranet, medio por el que se accede al catálogo de sus fondos y facilita las búsquedas ${ }^{38}$. Con ocasión del Bicentenario de la Guerra de la Independencia y realizado por un equipo coordinado por Fernando Torra, entonces Director de la Biblioteca Militar del IHCM, se han localizado fondos bibliográficos en las bibliotecas de Defensa sobre la guerra, publicándose una obra específica con un total de 1477 títulos $^{39}$. Un trabajo similar se ha editado con respecto a los fondos cartográficos históricos que conserva el Ejército ${ }^{40}$.

Sin embargo, y de nuevo en el ámbito de la investigación en historia militar, encontramos una producción editorial relevante y, en muchas ocasiones, de referencia, producto de la organización de foros científicos nacionales e internacionales sobre Historia Militar, muchos de ellos encuentros históricos organizados en torno a determinadas conmemoraciones históricas. En este sentido, son ya un referente clásico de la historiografía militar española las Actas en las que se han publicado Ponencias y Comunicaciones de los Congresos de Historia Militar, celebrados en Zaragoza, con una periodicidad no reglada desde el año 1996 en adelante y organizados por la Universidad de Zaragoza y la Academia General Militar, a través de la Cátedra Palafox ${ }^{41}$.

36 Herrero Fernández-Quesada, M. ${ }^{a}$ D., Macía Martín, A. y Martínez Cortés, I.: Fondos documentales de la Guerra de la Independencia en la Colección Blake del Archivo General Militar de Madrid, Madrid, Ministerio de Defensa, 2011.

37 García Hourcade y Valles Garrido, op. cit. (n. 6); Herrero Fernández-Quesada, M. a D.: Catálogo de la Biblioteca del Real Colegio de Artillería de Segovia. II. Fondos artilleros y de fortificación, Segovia, BCA, 1992; Marcelo, G. de: Fondos Geográficos, Segovia, BCA, 2003.

38 Resulta de gran utilidad como herramienta de localización de fondos la consulta en bibliodef, dentro del Portal de Cultura de Defensa

39 Bibliografía de la Guerra de la Independencia, Madrid, Ministerio de Defensa-Ollero y Ramos editores, 2008.

40 Cartografía de la guerra de la Independencia, Madrid, Ministerio de Defensa-Ollero y Ramos editores, 2008.

41 VV.AA.: Actas del Primer Congreso de Historia Militar, Zaragoza, AGM-Universidad de Zaragoza, 1986, 2 tomos; Actas del II Congreso de Historia Militar, Zaragoza, AGM-Universidad de Zaragoza, 1989, 2 tomos; y Actas del III Congreso Internacional de Historia Militar, Zaragoza, AGM-Universidad de Zaragoza, 1997. 
De la misma forma, fue en la Universidad de Sevilla en coordinación con la entonces Capitanía General, donde se institucionalizó la segunda Cátedra de Historia Militar, la General Castaños que celebró las V Jornadas de Historia Militar sobre los hechos histórico-militares relevantes en el Mediterráneo, con la edición de las Actas que también se han convertido en lectura y cita obligada ${ }^{42}$.

Entre los foros de encuentro y análisis para la historia militar española, cabe destacar el Congreso organizado en 1992 por Enrique Giménez y Emilio Balaguer en la Universidad de Alicante y la publicación de sus Actas sobre Ejército, Ciencia y Sociedad en la España del Antiguo Régimen ${ }^{43}$. Lo mismo ocurre con la edición que ha recogido el Congreso de la Asociación Internacional de Museos de Armas y de Historia Militar (IAMAN) que se celebró en España en 199444. De la misma forma, tiene interés la reunión científica organizada por la Fundación Berndt Wistedt, coordinada por Martínez Ruiz, Pi Corrales y Torrejón en Cádiz en 2000, sobre los Ejércitos y las Armadas de España y Suecia de 1750 a 1870, cuyas Actas se han convertido también una cita frecuente entre los especialistas ${ }^{45}$. Finalmente, destacaremos el Congreso organizado en 2005 por el CSIC y la Fundación Carolina sobre la Guerra y la Sociedad en la Monarquía Hispánica ${ }^{46}$. Capítulo aparte merecerían todas las Actas de los múltiples foros, congresos, seminarios, encuentros y reuniones científicas que se han organizado más recientemente en torno al Bicentenario de la Guerra de la Independencia, imposibles de referenciar aquí por razones de espacio.

Y dejando al margen los Congresos y Seminarios sobre Historia militar también hay que destacar obras colectivas -aunque en número mucho mas reducido- en las que participan varios autores de reconocido prestigio de notable interés como la de Bañón y Barker sobre los ejércitos y la sociedad en España ${ }^{47}$.

Finalmente, como dato indicativo de la proliferación de nuevos estudios sobre historia militar y su interés historiográfico, no podemos pasar por alto que en diferentes revistas universitarias sobre Historia Moderna, se han publicado importantes trabajos de cita obligada. Incluso se han dedicado números monográficos a esta línea de investigación, como el extraordinario de Manuscrits (2003) dedicado precisamente a historiografía; o los números 27 y 28 de Studia Histórica. Historia Moderna; o el número 22 de la Revista de Historia Moderna. De la misma forma, cabe recordar aquí la Revista de Historia Militar, de larga trayectoria y desigual producción, de la que merecen ser reseñados los interesantes números extraordinarios que se han editado recogiendo las ponencias de las sucesivas Jornadas de Historia sobre la Guerra de la Independencia que ha organizado el Instituto de Historia y Cultura Militar en los

\footnotetext{
42 Actas de las V Jornadas Nacionales de Historia Militar: El Mediterráneo: hechos de relevancia histórico-militar y sus repercusiones en España, Sevilla, 1995.

43 Balaguer, E. y Giménez, E. (eds).: Actas del Congreso sobre ejército, ciencia y sociedad en la España del Antiguo Régimen, Alicante, Universidad de Alicante-Fundación J. Gil-Albert, 1995.

44 Actas del Congreso Internacional de Museos de Armas y de Historia Militar (IAMAN), $\mathrm{n}^{\mathrm{o}}$ extraordinario de Militaria, Madrid, UCM, 1995.

45 Martínez Ruiz, E., Pi Corrales, M. de P. y Torrejón Chaves, J. (eds.): Los Ejércitos y las Armadas de España y Suecia en una época de cambios (1750-1870), Madrid, 2001.

46 Actas del Congreso Internacional Guerra y Sociedad en la Monarquía Hispánica, Madrid, 2007.

47 Bañón Martínez, R. y Barker, T. (eds.): “Armed forces and Society in Spain”, Past and Present, New York, 1995.
} 
últimos años; así como el también excelente número extraordinario de esta revista dedicado a las Fuentes y a la investigación en Historia Militar (2002).

A pesar de todo ello, debemos poner de manifiesto aquí que aún son escasas las obras de síntesis generales, aunque se están realizando trabajos sobre aspectos sociales de los ejércitos, como los ya citados de Andújar; y otros mas monográficos centrados en un acotado marco geográfico, muy reseñables como los editados sobre Galicia, Aragón, Valencia o Granada. Por limitaciones en la extensión de este artículo, no es posible ser prolijos y realizar un repertorio de la historiografía militar española en los últimos treinta años, que cuenta ya con una producción ciertamente reseñable. Sin embargo, no podíamos cerrar este epígrafe sin citar a los que se han convertido en autores de referencia, ellos y sus obras, para los investigadores de la historia militar. Sin duda, hoy la nómina de historiadores españoles que han dedicado parte o la totalidad de sus investigaciones y su obra a la historia militar en la Edad Moderna, es amplia desde Ladero, Maravall, Corona, Seco Serrano, Domínguez Ortiz, a Cepeda, Ribot, Martínez Ruiz, Solano, Giménez, Pi Corrales, Borreguero, Andújar, García Hernán, Saavedra, Jiménez Estrella...

En 1988 con ocasión del Bicentenario de Carlos III, en el Congreso Internacional que organizó el Departamento de Historia Moderna de la UCM, en la sección sobre historiografía ya se dedicó un espacio al estado de la cuestión en historia militar y resultaba ser esperanzador de cara al futuro, sin embargo, en su ponencia sobre $E l$ Ejército español en el siglo XVIII, el profesor Cepeda Gómez, además de hacer un repaso a la historiografía mas relevante hasta aquel momento reflexionaba sobre el presente y futuro de la historia militar en España. Y el análisis iba acompañado de una cierta justificación, casi reivindicación -por otra parte necesaria en aquellos momentos aún-, de los estudios sobre los ejércitos en el ámbito académico, para terminar apuntando vías de investigación que después han sido trabajadas ferazmente a lo largo de los años posteriores ${ }^{48}$. De tal manera que, hoy bien podemos afirmar que en la Universidad española se cuenta con un ya amplio elenco de historiadores que han desarrollado sus estudios en el marco de la Historia Militar.

En cuanto a las líneas de investigación sobre los ejércitos que se abrían a medio y largo plazo, Cepeda señalaba entonces la historia social militar, el análisis del papel de los militares en la Administración Borbónica y el predominio de las tropas de la Casa Real, la procedencia social de los cuadros de mando de los ejércitos y las posibilidades de promoción social; los entresijos del reclutamiento; las relaciones del generalato con el poder y lo que después se ha definido como el sistema de redes clientelares que les catapultaba a puestos importantes de la Administración, con los daños colaterales y tensiones que se generaron con los políticos hoy por todos conocidos; las repercusiones y aportaciones de las actividades militares en diferentes

48 CEPEDa Gómez, J.: "El Ejército español en el siglo XVIII", en Actas del Coloquio Internacional de Carlos III y su siglo. Madrid, UCM, 1989. tomo I. pp.557-564. Este autor, son posterioridad ha seguido trabajando sobre la historiografía militar y de la Armada, cabe citar aquí su trabajo "La historiografía sobre la Marina en los siglos XVIII y XIX", en Revista de Historia Naval, así como su excelente estudio "Una memoria recuperada. Las 'hijas de la libertad' en la actual historiografía de la revolución americana", en Capel Martínez, R. M. a (ed.): Presencia y visibilidad de las mujeres: recuperando historia, Madrid, Abada editores, 2013, pp. 77-104. 
ámbitos de la sociedad civil, o la estrecha vinculación de las actividades científicas y militares en la España Ilustrada. Por cierto, que una reivindicación compartida con él por aquellos que nos hemos dedicado a la investigación en historia militar era la puesta en marcha de una Cátedra de Historia Militar que, por fin, a finales de 2012 se ha formalizado entre el Jefe del Estado Mayor del Ejército, General de Ejército Domínguez Buj y el Rector de la UCM, José Carrillo, como Cátedra Extraordinaria.

En este epígrafe solo podemos apuntar y extractar las líneas de investigación trabajadas más recientemente con excelentes resultados y que han permitido el desarrollo de la nueva corriente historiográfica con estudios sobre los ejércitos y la guerra en la Edad Moderna insertados en un marco teórico, metodológico e interpretativo integrador, mucho mas amplio. En el contexto de la historiografía militar europea, nos interesa especialmente el caso español para el que las obras tantas veces citadas de Parker, Thompson, Quatrefages, Roberts, Corvisier, Robson o Hale han marcado con claridad el punto de partida y el rumbo de las investigaciones sobre los ejércitos, de la misma forma, por otra parte, que los ya clásicos en nuestro país de Ladero ${ }^{49}$, Maravall ${ }^{50}$, Corona $^{51}$ o Domínguez Ortiz $^{52}$ como pioneros e innovadores a la hora de integrar en sus estudios generales sobre la Edad Moderna el devenir de los ejércitos.

La nueva historia militar rompió con el andamiaje clásico de las historias de la guerra tradicionales, o meramente institucionales, casi notariales, porque limitaron sus aportaciones a la cuantificación de unidades, y de contingentes humanos y armamentísticos. Y la brecha se ha abierto -siguiendo por otra parte las tendencias historiográficas de nuestro entorno- en la historia social de los ejércitos con notables estudios que han analizado la procedencia social de los militares, sus rentas, el origen geográfico y su incidencia en el reclutamiento, en el servicio de las armas como medio de promoción social en virtud de la patrimonialización, su cercanía al poder y amplias competencias de naturaleza diversa, o del reclutamiento privado o de la venalidad de los cargos en los ejércitos.

Con respecto a la procedencia nobiliaria, el acceso endogámico a la institución y el ingreso en la carrera de las armas como sistema de promoción social, cabe recordar los trabajos de García Hernán ${ }^{53}$ o Morales Moya ${ }^{54}$; y por lo que concierne a los estudios sobre prosopografía e historia social de la milicia, sin duda, constituyen ya un conjunto compacto y muy notable los estudios de Francisco Andújar sobre la composición social de los ejércitos dieciochescos, el Consejo de Guerra, los Capitanes

49 Ladero Quesada, M. A. (coord.): Los recursos militares en la Edad Media Hispánica, Madrid, 2001, obra en la que este historiador publica un estudio sobre "Recursos militares y guerras de los Reyes Católicos.

50 Maravall, J. A.: Escritos de Historia Militar. Recopilación y estudios introductorios de Carmen Iglesias y Alejandro Diz, Madrid, Ministerio de Defensa, 2007.

51 Corona Baratech, C.: Revolución y reacción en el reinado de Carlos IV, Madrid, Rialp, 1957.

52 Domínguez Ortiz, A.: La sociedad española en el siglo XVIII, Madrid, CSIC, 1955; y Sociedad y Estado en el siglo XVIII español, Barcelona, Ariel, 1976.

53 García Hernán, D.: "La función militar de la Nobleza en los orígenes de la España Moderna" en Gladius, XX, (2000); y "Felipe II y el levantamiento de tropas señoriales", en Felipe II (1598-1998). Europa dividida: La Monarquía Católica de Felipe II, vol. 2, Madrid, 1999.

54 Morales Moya, A.: "Milicia y nobleza en el siglo XVIII", Cuadernos de Historia Moderna, 9 (1988), pp. $122-137$. 
Generales y el índice de venalidad de los cargos militares en el ejército borbónico, que citamos después.

De la misma forma, en estos años se ha estudiado el ejército y la política, el acercamiento de la oficialidad a los cargos de poder, y el devenir de instituciones como las milicias o cuerpos de defensa locales en un marco de actuación política cuyo control estaba en manos de las oligarquías locales. En este sentido, señalaremos aquí los trabajos de Cepeda Gómez ${ }^{55}$, Martínez Ruiz, Pi Corrales, o Contreras Gay sobre las tropas concejiles y las milicias provinciales. El ejército, la administración militar o los órganos territoriales se convirtieron en un espacio de actuación política controlados por las élites y redes clientelares desde las instituciones castrenses territoriales y locales hasta llegar a la propia Corte, ya fuera con la Monarquía Hispánica o con el advenimiento de los Borbones al trono español. En este sentido, los trabajos que inició Didier Ozanam ${ }^{56}$ y después otros historiadores como Jean P. Dedieu y $\mathrm{M}^{\mathrm{a}}$ Victoria López Cordón ${ }^{57}$ sobre las instituciones del estado y el entramado de poder y funcionarial al mas alto nivel, han dado cobijo a investigaciones sobre los militares en aquel entorno, sus conexiones en el sistema de redes clientelares y la parcela que ocuparon. De nuevo, aquí también hay que recordar la obra de Andújar ${ }^{58}$.

Precisamente en este marco de trabajo contamos con algunos estudios muy reseñables acotados geográficamente y centrados en alguna zona como Galicia, Valencia, Granada o Aragón, son las obras monográficas de Saavedra ${ }^{59}$, Pardo Molero ${ }^{60}$, Mo-

55 Cepeda Gómez, J.: "La época de Carlos IV: crisis del Ejército Real Borbónico", en Fuerzas Armadas Españolas, Madrid, Alhambra, 1985. tomo II; "La crisis del Ejército Real y el nacimiento del Ejército Nacional", en Actas del Congreso sobre Ejército, Ciencia y Sociedad, Universidad de Alicante y Fundación Juan Gil Albert, 1993; "El Ejército de Carlos IV" en Aproximación a la historia militar de España, Madrid, Ministerio de defensa, 2006.

56 Concretamente el epígrafe que dedicó al Ejército como instrumento de la política exterior de Felipe $\mathrm{V}$ en su trabajo sobre "La política exterior de España en tiempo de Felipe V y de Fernando VI", editado en la Historia de España de Menéndez Pidal, Madrid, Espasa Calpe, 1985, tomo XXIX-I.

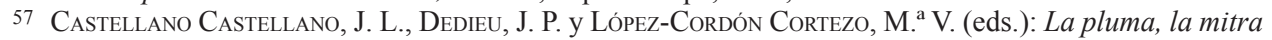
y la espada. Estudios de historia institucional en la Edad Moderna, Madrid, Marcial Pons, 2000.

58 Andúuar Castillo, F.: Los militares en la España del siglo XVIII, Granada, Universidad de Granada, 1991; "Elites de poder militar: las Guardias Reales en el siglo XVIII", en Castellano Castellano, J. L.,

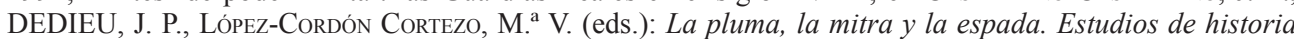
institucional en la Edad Moderna. Madrid, Marcial Pons, 2000; o Consejo y Consejeros de Guerra en el siglo XVIII, Granada, Universidad de Granada, 1996.

59 SaAvedra Vázquez, $M^{\text {a }}$ del C.: "La política militar de la Monarquía y sus efectos en Galicia (15561648), Obradoiro de Historia Moderna, 3 (1994), pp. 163-186; "Los protagonistas de la actividad militar en Galicia: Nobleza, ciudades y juntas del Reino (ss. XVI y XVII)", en JimÉnez Estrella, A. y AndúJaR CASTILlo, F.: Los nervios de la guerra. Estudios sociales sobre el ejército de la Monarquía Hispánica (s. XVI-XVIII). Nuevas perspectivas, Granada, Comares, 2007; y "Algunos rasgos del comportamiento religioso de los militares españoles en época austríaca: el ejemplo de La Coruña", Espacio, Tiempo y Forma, 7 (1994), pp. 271-286.

60 "Los ejércitos de su majestad. La movilización de tropas reales en Valencia a comienzos del reinado de Carlos I (1521-1526)", en XV Congreso de Historia de la Corona de Aragón (siglos XIV-XVI), Zaragoza, 1993; y su obra sobre La defensa del Imperio. Carlos V, Valencia y el Mediterráneo, Madrid, 2000. 
las $^{61}$, Giménez ${ }^{62}$, Corona Marzol ${ }^{63}$, Contreras Gay ${ }^{64}$, Solano ${ }^{65}$, Armillas ${ }^{66}$ o Jiménez Estrella $^{67}$, muy centrados en la articulación de sus respectivos sistemas defensivos. De la misma forma, en Salamanca un grupo de historiadores están realizando investigaciones sobre esta ciudad y su ámbito territorial y la guerra en la Edad Moderna. ${ }^{68}$ Y desde la perspectiva de la historia del Derecho, hay que recordar las notables aportaciones entre otros de Domínguez Nafría ${ }^{69}$.

Por otra parte, cabe destacar aquí otra de aquellas vías de investigación apuntadas a finales de los 80 y que se ha trabajado en los últimos años, la que trata de desentrañar los nudos de conexión entre la guerra y las estructuras hacendísticas, históricamente marcados por la continua demanda de partidas presupuestarias para la dotación de los ejércitos que cubrían los diferentes territorios de la Monarquía y el mantenimiento de su sistema defensivo, y para las guerras, naturalmente ${ }^{70}$. La demanda de liquidez era continua para el mantenimiento del aparato logístico, en definitiva, se ha investigado también todo aquello que giraba en torno al costo de la guerra, o más ajustadamente al precio de la guerra, siguiendo a Yun ${ }^{71}$.

Como no podía ser de otra manera, también se ha revisado historiográficamente la orgánica de los ejércitos y sus procesos evolutivos, ámbito destacando para América

61 Molas Ribalta, P.: "Militares y togados en la Valencia Borbónica", en Historia social de la administración española, Barcelona, 1980.

62 Giménez López, E.: Militares en Valencia (1707-1808). Los instrumentos del poder borbónico entre la Nueva Planta y la crisis del Antiguo Régimen, Alicante, 1990.

63 Corona Marzol, C.: "Burguesía y milicia. El sistema defensivo de Valencia en el siglo XVIII", en Millars, IX, 1986-1987.

64 Contreras Gay, J.: Problemática militar en el interior de la Península durante el siglo XVII. El modelo de Granada como organización militar de un municipio, Madrid, 1980; Las milicias provinciales en el siglo XVIII: estudio sobre los regimientos de Andalucía, Almería, 1993.

65 Solano Camón, E.: Ejército y sociedad. La defensa del Reino de Aragón en la Edad Moderna. Zaragoza, 1986; y "los reinos orientales en la organización militar de la monarquía española en la época del Barroco", en Martínez Ruiz, E. y Pi Corrales, M. de P.: España y Suecia en la época del Barroco (1600-1660), Madrid, 1998.

66 Armillas Vicente, J. A.: "la Compañía suelta de Fusileros de Aragón (1762-1788)", en Homenaje al Doctor Sebastián García Martínez, Valencia, 1990.

67 Jiménez Estrella, A.: "Linajes y alcaides en el Reino de Granada bajo los Austrias. ¿Servicio militar o fuentes de enriquecimiento y honores?", en JimÉnEz Estrella, y Andúuar CASTillo, op. cit. (n. 59).

68 VV.AA.: La guerra en la Historia. Salamanca, 1999.

69 Domínguez Nafría, J. C.: "Consejo de guerra y desarrollo de las estructuras militares en tiempos de Felipe II", en Las Sociedades Ibéricas y el Mar a finales del siglo XVI, vol. II: La monarquía, recursos, organización y estrategias, Madrid, 1998. Este autor profundizó en la institución en su Tesis Doctoral, siguiendo la línea de su maestro José A. Escudero.

70 En este sentido abrió brecha Miguel A. LADERO QuESADA con su trabajo Milicia y economía en la guerra de Granada: el cerco de Baza, Valladolid, 1964. Por citar alguno de los estudios mas recientes sobre el tema incluimos aquí la obra de AndúJar CAstillo, F.: El sonido del dinero. Monarquía, ejército y venalidad en la España del siglo XVIII, Madrid, Marcial Pons, 2004. De la misma forma, en la última obra como editor, sobre Los nervios de la guerra, este autor ha integrado también un capítulo sobre guerra y economía o economía de la guerra como uno de los nervios fundamentales que dan vida al sistema militar, JIMÉNEZ EsTRELLA y ANDÚJAR CAstillo, op. cit. (n. 59), firmado por Alonso García, D.: “Guerra, hacienda y política. Las finanzas militares en los inicios de la Edad Moderna".

71 Yun Casalilla, B.: Marte contra Minerva. El precio del Imperio español, c. 1450-1600, Barcelona, Crítica, 2004. 
la obra de Juan Marchena ${ }^{72}$; para los contingentes militares de los Austrias, las investigaciones de Ribot $^{73}$ y para los tercios en concreto algunas aportaciones como la de $\mathrm{Albi}^{74}$. En cuanto al tratamiento historiográfico del reclutamiento, resulta imprescindible la obra de Cristina Borreguero ${ }^{75}$, así como las aportaciones de Ofelia Rey ${ }^{76}$, Ribot o Contreras Gay ${ }^{77}$, y Puell de la Villa ${ }^{78}$. Además, merecen una mención especial los trabajos de Solano Pérez Lila ${ }^{79}$, Martínez Ruiz y Pi Corrales ${ }^{80}$ y Cepeda ${ }^{81}$; y después de los alumnos de estos últimos, más monográficos, como el coordinado por Enrique García Hernán sobre la presencia de extranjeros en el ejército español ${ }^{82}$.

Asimismo, es importante incluir aquí el estudio de algunas instituciones de prestigio enfocadas a la formación de los cuadros de mando y a la institucionalización de la enseñanza militar en España ${ }^{83}$, estrechamente vinculado a las actividades científicas y técnicas. La ciencia y la milicia ${ }^{84}$, así como su relación e incidencia en la innovación

72 Marchena Fernández, J.: " El ejército americano y la política de España en América" en Fuerzas Armadas españolas. Historia institucional y social, Madrid, Alhambra, 1986. tomo II.

73 Riвот, L.: "Las provincias italianas y la defensa de la Monárquica” Manuscrits, 13 (1995), pp. 97-122; "Milán, plaza de armas de la Monarquía” Investigaciones Históricas, 10 (1990), pp. 203-238.

74 Albi de la Cuesta, J.: De Pavía a Rocroi: los tercios de infantería española en los siglos XVI y XVII, 1999, aunque después de la obra de René QuATREFAGES, ya nadie parecía investigar sobre los tercios.

75 Borreguero Beltrán, C.: El reclutamiento militar por quintas en la España del siglo XVIII. Orígenes del servicio militar obligatorio, Valladolid, 1989.

76 Rey Castelao, O.: "Hombres y ejército en Galicia. La leva de 1762", Espacio, Tiempo y Forma, 7 (1994), pp. 199-224.

77 Riвot, L.: "El reclutamiento militar en España a mediados del siglo XVII. La composición de las milicias de Castilla", Cuadernos de investigación histórica, 12 (1989); y Contreras GAY, J.: "El siglo XVII y su importancia en el cambio de los sistemas de reclutamiento durante el Antiguo Régimen", Studia Histórica. Historia Moderna. 14 (1996), pp. 141-154.

78 Puell de la Villa, F.: El soldado desconocido: de la leva a la "mili” (1700-1912), Madrid, 1996.

79 "Los orígenes de los Reales Ejércitos. Reformismo y planificación", en Fuerzas Armadas Españolas. Historia institucional y social. Madrid, Alhambra, 1986.

80 Martínez Ruiz, E.: “Las Fuerzas Armadas entre la revolución y la restauración”, en Fuerzas Armadas Españolas, Historia institucional y social. Madrid, Alhambra, 1986; "Perfiles de un ejército español de reserva. Las ordenanzas de guardas de 1613”, en Martínez-Ruiz, E. y Pi Corrales, M. de P. (eds): España y Suecia en la época del Barroco (1600-1660). Madrid, 1998; y más recientemente Los soldados del Rey. Madrid, Actas, 2008, además Martínez Ruiz, E., Pi Corrales, M. de P. y Torrejón Chaves, J. (eds): Los ejércitos y las armadas de España y Suecia en una época de cambios (1750-1870), Madrid, 2001. De igual forma, PI Corrales, M. de P.: "Las Ordenanzas de las Guardas y la búsqueda de una élite militar", en Martínez Ruiz, E. (coord.): Poder y mentalidad en España e Iberoamérica (siglos XVI-XX), Madrid, 2000.

81 En sus diferentes trabajos, ya citados aquí con anterioridad.

82 García Hernán, E. y Recio Morales, O. (coords): Extranjeros en el Ejército. Militares irlandeses en la sociedad española, 1580-1818. Madrid, Ministerio de Defensa, 2007.

83 Muñoz Corbalán, J. M.: Los ingenieros militares de Flandes a España (1691-1718), Madrid, 1993.

84 En esta línea de investigación hay que partir de los epígrafes dedicados a la relación entre las actividades científicas y militares en las obras generales y ya clásicas de relevantes historiadores de la ciencia como Peset o López Piñero. Con posterioridad se ha trabajado lo referente a los Ingenieros Militares, no por investigadores dedicados propiamente a la historia militar, como Capel y su equipo. Para el Cuerpo de Artillería vid. la publicación de nuestra tesis doctoral Herrero FernándeZ-Quesada, M. ${ }^{a}$ D.: Ciencia y milicia en el siglo XVIII. Tomás de Morla, artillero ilustrado, Segovia, PAS, 1992; así como para las instituciones de enseñanza militar, La enseñanza militar ilustrada. El Real Colegio de Artillería de Segovia, Segovia, BCA, 1990; "la formación de la oficialidad en el siglo XVIII”, en Martínez Ruiz, Pi Corrales, y Torrejón Chaves, op. cit. (n. 80); o "Breve aproximación a la historia de la enseñanza militar", en Aproximación a la historia militar de España, Madrid, Ministerio de Defensa, 2006. vol. III. 
en los procesos fabriles relacionados con la industria militar en España ${ }^{85}$ (sobre lo que ha marcado un antes y un después la obra de José Alcalá Zamora de las fábricas de cañones para la marna de Liérganes y La Cavada); y sin duda, con la arquitectura militar. De hecho, en poco mas de una década, ha aumentado el interés por el universo de los ingenieros militares, las fortificaciones y obras del sistema defensivo de la Monarquía Hispánica ${ }^{86}$. Sin duda, lindando con ello, en los últimos años se han editado notables trabajos sobre cultura y guerra, la tratadística, los militares escritores, su producción y las aportaciones de la milicia en este ámbito, tantas veces tópicamente contrapuesto (la pluma y la espada) o forzadamente unido. En este sentido, recordaremos como representativos los estudios de David García Hernán ${ }^{87}$ sobre la trascendencia de la tratadística militar clásica, entre otros; o los que nos han llegado desde la filología firmados por Manuel-Reyes García Hurtado ${ }^{88}$ y mas recientemente por Joaquín Álvarez Barrientos ${ }^{89}$.

Por fin, y marcando tendencia historiográfica debemos señalar alguna obra coral reciente que reúne los últimos trabajos y estudios sobre las diferentes líneas de investigación mencionadas, y coordinadas por especialistas, como la publicación editada por Andújar y Jiménez Estrella ${ }^{90}$, titulada con acierto Los nervios de la guerra, que da cabida a varios de los aspectos que articulan y conexionan el sistema militar español en la Edad Moderna.

85 Alcalá-Zamora Y Queipo de Llano, J.: Historia de una empresa siderúrgica española: los altos hornos de Liérganes y la Cavada, 1622-1834, Santander, 1974. Años después hay que recordar el trabajo de RABANAL Yus, A.: Las Reales Fundiciones Españolas del siglo XVIII, Madrid, 1990. Y más recientemente, una visión de conjunto del proceso evolutivo de las fábricas militares españolas en Herrero Fernández-QuesadA, M. ${ }^{\mathrm{a}}$. D.: "La ciencia y la técnica militar", en Aproximación a la historia militar de España, Madrid, Ministerio de Defensa, 2006. vol. III.

86 Este ámbito tan específico también ha sido analizado en las últimas décadas, destacando los numerosos trabajos de Alicia Cámara, vid. CÁMARA MuÑoz, A.: "La arquitectura militar y los ingenieros de la monarquía española: aspectos de una profesión”, en Revista de la Universidad Complutense, 3 (1981), pp. 255-269; o "la fortificación en la Monarquía de Felipe II", en Espacio, Tiempo y Forma, 2 (1989), pp. 73-80; así como la publicación conmemorativa que ha supuesto una puesta al día de algunos momentos concretos de la historia de la fortificación, como la que coordinó Hernando SÁnchez, C. J. (coord.): Las fortificaciones de Carlos V, Madrid, 2000 .

87 García Hernán, D.: "Historiografía y fuentes para el estudio de la guerra y el ejército en la España del Antiguo Régimen", Revista de Historia Militar, n extraordinario. Madrid, IHCM, 2002, donde dedica un buen número de páginas al estudio de la tratadística y a las obras de carácter general en la Edad Moderna; y "la cultura de la guerra en la Europa del Renacimiento. Algunas perspectivas de estudio", en Revista de Historia Social, 44 (2002), pp. 105-124.

88 García-Hurtado, M. R.: El arma de la palabra. Los militares españoles y la cultura escrita en el siglo XVIII (1700-1808), Coruña, Universidad dela Coruña, 2002; Traduciendo la guerra, La Coruña, Universidad de La Coruña, 1999.

89 Álvarez Barrientos, J. (ed.): La guerra de la Independencia en la cultura española, Madrid, Siglo XXI, 2008; y el epígrafe sobre el tema en Los hombres de letras en la España del siglo XVIII. Apóstoles y arribistas, Madrid, Ed. Castalia, 2006.

90 Jiménez Estrella y AndúJar Castillo, op. cit. (n. 59). 


\section{EL ARCHIVO GENERAL MILITAR DE SEGOVIA, DECANO DE LOS ARCHIVOS HISTÓRICOS MILITARES}

\subsection{SOBRE LA HISTORIA DE LA INSTALACIÓN DEL ARCHIVO GENERAL MILITAR EN EL ALCÁZAR DE SEGOVIA}

El alcázar no es el primer edificio con un pasado histórico cargado que, con el tiempo, se ha visto inmerso en un proceso de reconversión en su uso. Particularmente, nos referimos a antiguos castillos, palacios y fortalezas, después prisiones de estado y finalmente adaptados para acoger archivos, precisamente depósitos documentales de la historia de España. En la memoria de todos, como pionero se encuentra el Archivo General de Simancas.

El caso del AGMS responde a un proceso similar pero con singularidades en las que merece la pena detenerse siquiera brevemente. ¿Por qué se elige esta fortaleza para la instalación del primer Archivo General Militar en 1898? Las claves son varias pero tienen que ver y mucho con que en la segunda mitad del siglo XVIII, Carlos III decidió dar un giro al devenir de su historia y fundar allí el Real Colegio de Artillería ${ }^{91}$ que inició su andadura el 16 de mayo de 1764 dirigido por el ilustrado Conde Félix de Gazola ${ }^{92}$. Con esta academia se institucionalizó la enseñanza militar de la artillería en la Ilustración y se acuñó un modelo de centro docente científico-militar que rápidamente consolidó su prestigio no solo en España, sino también en la Europa Ilustrada. Sin embargo, el 6 de marzo de 1862 se produjo un incendio que dañó el edificio en especial sus cubiertas, aunque en menor medida la estructura de su fábrica, pero que sin embargo determinó la salida del colegio militar hacia el convento de San Francisco en Segovia.

En unos años en los que intervino la Comisión de Monumentos para evitar la venta de las ruinas del antiguo palacio, fue declarado Monumento Nacional pasando a depender de los Ministerios de Fomento y Hacienda que se hicieron cargo de los gastos de las obras de rehabilitación ${ }^{93}$ con la intervención de la Comandancia de Ingenieros y finalmente siguiendo el proyecto de dos arquitectos municipales, Bermejo y Odriozola. Superadas tan serias dificultades, curiosamente, el problema se planteó a la hora de darle un nuevo uso ${ }^{94}$. En esto pesó y mucho la estrecha relación de la fortaleza con el Cuerpo de Artillería que solicitó al Estado la devolución del edificio.

Este asunto planteó un debate en el que se implicaron artilleros, autoridades civiles, académicos y eruditos locales que volcaron en publicaciones diversas y cola-

91 Herrero Fernández-Quesada, M. ${ }^{a}$ D.: La enseñanza militar ilustrada. El Real Colegio de Artillería de Segovia. Segovia, PAS, 1990. Desde entonces he seguido la investigación sobre este centro con ponencias y publicaciones diversas entre las que solo citaré la última que aún está en prensa "La formación de los militares en el siglo XVIII. El Colegio Artillero de Segovia o la creación de un modelo”, en una obra que edita Sílex y que está coordinada por José M. ${ }^{a}$ Imícoz Beunza.

92 Herrero Fernández-Quesada, M. a D.: Voz "Félix Gazola”, en Diccionario Biográfico Español. RAH, 2009, tomo XXII, pp. 667-672.

93 Sobre los avatares de aquellos años postreros al incendio y sobre la restauración del alcázar segoviano, encontramos documentación el AGMS, sección $2^{a}$, división 10 ${ }^{a}$, leg. 45.

94 Oliver Copons, E.: El Alcázar de Segovia. Monografía histórica, Valladolid, 1916. 
boraciones en prensa sus inquietudes e ideas para el futuro del alcázar ${ }^{95}$. Como dato ilustrativo, debemos recordar aquí que trascendió las fronteras provinciales y que incluso el historiador y académico, pero también artillero, José Gómez Arteche y Moro $^{96}$-autor de la voluminosa obra ya clásica sobre la Guerra de la Independencia Española ${ }^{97}$ - realizó un informe a la Academia de la Historia al respecto. Pero lo cierto es que aún polemizando sobre tan importante decisión, ya en 1896 se traslada a la fortaleza un archivo, el del Cuerpo de Artillería, aunque afortunadamente no su Parque de Artillería que habría amenazado los cimientos del alcázar recién rehabilitado.

Y paradójicamente la polémica más enconada se planteó dentro de la propia institución militar porque con el archivo artillero ya en el alcázar, por un Real Decreto de la Regencia, la Reina $\mathrm{M}^{\mathrm{a}}$ Cristina mandaba fundar el Archivo General Militar en el Alcázar de Segovia. Mientras los artilleros aspiraban a lograr la devolución al Cuerpo de Artillería del edificio donde estuvo casi cien años el Colegio y en sus mejores años. No solo no querían perder su vinculación emocional, sino la propiedad del alcázar, amenazada al ser ocupado por unos inquilinos no deseados, los legajos con la documentación histórico-militar y los militares encargados de su custodia y conservación. Sin nada resuelto, con el cambio de siglo continuó el proceso de formación del AGMS, instalándose estantes en diferentes salas del antiguo palacio, pues -como veremos- la entrada de documentación era incesante en aquella primera etapa de su historia.

Pero los artilleros no cejaron en su empeño y aprovechando la conmemoración institucional del Primer Centenario de la Guerra de la Independencia, solicitaron al Rey en su visita a Segovia de 6 de mayo de 1908 y durante un almuerzo en la Academia de Artillería, que se devolviera al Cuerpo de Artillería la que fue su "casa solariega", consiguiendo su propósito y la formalización legal que salió publicada en Real Orden de 19 de mayo de 1908, enfatizándose en este texto la "provisionalidad" de la presencia del archivo entre los muros del Alcázar ${ }^{98}$.

Así "el archivo continuaría en aquel lugar de manera interina, hasta que pudiera trasladarse a otro local que reuniera las condiciones necesarias" $" 99$, y de forma temporal este inquilino llegó a convertirse en más que centenario. Lo cierto es que, por fin el 20 de febrero de 1909 el entonces Director de la Academia de Artillería, Gabriel Vidal y Ruby -apasionado de la historia del arma y de la fortaleza en la que se formó como alumno ${ }^{100}$, tomó posesión del Alcázar en nombre del Cuerpo de Artillería.

95 Lecea y García, C.: El Alcázar de Segovia. Su pasado, su presente, su destino mejor. Segovia, 1891.

96 Herrero Fernández-Quesada, M. a D.: Voz "José Gómez de Arteche y Moro", en Diccionario Biográfico Español. RAH, 2009, tomo XXIII, pp. 330-333.

97 Gómez Arteche, J.: Guerra de la Independencia. Historia Militar de España. 1808 a 1814, Madrid, 1868.

98 Mas información al respecto encontramos en los trabajos ya citados de Díaz Garkido y OLIVER Copons, op. cit. (n. 94)

99 AGMS, sección $2^{a}$, división $10^{a}$, leg. 46 que reúne la documentación sobre este asunto.

100 A la pluma de Gabriel Vidal y Ruby se deben interesantes artículos publicados en el Memorial de Artillería, entre los que destacaremos solo uno de ellos, relacionado con el Alcázar tras el incendio y particularmente, la información que diariamente, in situ, recogió durante las obras de restauración del monumento, con aportaciones arqueológicas muy relevantes relativas a las piezas de artillería antigua que, debidamente recicladas, durante siglos permanecieron enterradas a la entrada de la fortaleza cumpliendo la misión de cañerías. Vid. VidAL y RUBY, G.: "Un hallazgo importante. Nota referente a una caña de cerbatana 
El Ayuntamiento de la ciudad buscó alternativas en Segovia y su provincia, comprometiéndose a aportar económicamente las obras de adaptación, por ejemplo del Monasterio de Santa María del Parral que, finalmente, se desechó. Otro edificio con posibilidades de haber albergado el archivo fue el Seminario Conciliar, antigua Casa de la Compañía de Jesús, pero este traslado se descartó porque como contrapartida el Consistorio debería levantar otro edificio para albergar el Seminario. Con el objetivo de mantener este Archivo Militar en los confines provinciales, se barajaron edificios en Cuellar, Sepúlveda, Santa María la Real de Nieva o Nava de la Asunción, sin que ninguna de aquellas opciones consolidara. Incluso otras provincias ofrecían alternativas, baste citar como ejemplo de todos ellos el Palacio del Infante Don Luis en Arenas de San Pedro, traza de Ventura Rodríguez que, curiosamente, también pasó a ser Seminario Conciliar.

Mientras, se modificaba la ubicación espacial de los legajos en la fortaleza, ante la toma de posesión del Cuerpo de Artillería que tenía sus propias ideas acerca de la ocupación. Aunque en principio se rechazó un primer traslado de fondos y liberación de estancias nobles ${ }^{101}$, no tardando mucho fue inevitable. Los artilleros instalaron en el interior de la Torre del Homenaje una sala dedicada a la historia a la faceta industrial del Cuerpo de Artillería, a la industria artillera y sus establecimientos mas señeros. En la misma torre - tras la rehabilitación- se acondicionó una Sala del Trono, especialmente para la recepción de los Reyes con ocasión del Primer Centenario. Y entretanto, en la planta principal del palacio viejo, en las estancias nobles, aún permanecían las estanterías con legajos, aunque progresivamente se irían vaciando para pasar al primer piso, sótanos y dependencias de la llamada "Casa de la Química", edificio neoclásico anejo al alcázar que se levantó como Real Laboratorio de Química que vino a dirigir el francés Luis Proust en $1792^{102}$.

En definitiva, los artilleros asumieron de nuevo la propiedad del edificio y conceptualmente lo entendieron como una extensión más de las dependencias de la Academia de Artillería con sede en el Convento de San Francisco. Lo cierto es que, a lo largo del siglo XX han mantenido con los responsables del archivo un pulso entre colegas por los metros cuadrados y estancias en disputa en la antigua fortaleza.

Mas aún, cuando después de más de cuarenta años el Alcázar necesitaba nuevas obras de mantenimiento y reparación que por entonces parece solo podía asumir el Ministerio de Educación Nacional. En consecuencia, por un Real Decreto de 18 de enero de 1951, se creó el Patronato del Alcázar de Segovia, cívico-militar, bajo la presidencia del Director de la Academia de Artillería, representantes de las instituciones locales -Ayuntamiento y Diputación- y del Ministerio de Educación. El Patronato es el organismo que desde entonces ha gestionado todo lo concerniente a la antigua

del final de la primera mitad del siglo XV, encontrada en el Alcázar de Segovia", en Memorial de Artillería, serie III, tomo XXVII, 1893. Sobre el seguimiento de las obras de restauración en el alcázar y los resultados arqueológicos de las mismas, véase también Herrero Fernández-Quesada, op. cit. (n. 19), capítulo 8 dedicado a "La formación de las colecciones del Museo Militar. Rastreo arqueológico de las piezas", pp. 131-162.

101 Vid. Oliver Copons en su monografía sobre el Alcázar ya citada (n. 94), da cumplida cuenta de la distribución de espacios y estancias para acoger los legajos y sus sucesivos traslados de ubicación, basándose en la misma documentación consultada para este artículo en AGMS, sección $2^{a}$, división 10 ${ }^{a}$,leg. 46.

102 Herrero Fernández-Quesada, M. ${ }^{\mathrm{a}}$ D.: Cañones y probetas en el alcázar. Un siglo en la historia del Real Colegio de Artillería (1764-1862), Segovia, PAS, 1993. 
fortaleza. Entre los objetivos fundacionales, fue prioritario la formación de un Museo que pusiera de manifiesto el importante pasado histórico del alcázar segoviano, encargándose este Patronato del acondicionamiento de las estancias nobles del ala norte del palacio, devolviéndoles el aspecto que tuvieron otrora y que hoy todos conocemos, ocupando el archivo otras salas de menor visibilidad. De nuevo, en este Reglamento se recordaba que el Archivo General Militar debía contar con instalaciones dignas aunque su ubicación en la fortaleza mantuviera aún el carácter de provisional. Hoy podemos decir que su interinidad ya es más que centenaria.

En nuestra opinión, ciento quince años en el alcázar han hecho del Archivo General Militar, su mayor activo patrimonial e histórico en el siglo XXI. Esto quedó particularmente refrendado en 1998, con ocasión del Centenario de la fundación del Archivo para cuya conmemoración se programaron diversos actos, entre ellos una Exposición en la Casa de la Química, siendo encargada por el IHCM como Comisaria. En aquella presentación documental, quedaron reflejadas las diferentes secciones en las que históricamente se ha articulado este archivo, con una selección de la tipología documental mas específica de la institución militar, junto a algunos fondos museísticos que fueron cedidos para la exposición por el Museo del Ejército ${ }^{103}$.

\subsection{FORMACIÓN Y PROCEDENCIA DE LOS FONDOS}

Un aspecto clave para entender la formación de los archivos militares es la procedencia de los fondos, por otra parte, criterio fundamental en la constitución de cualquier otro archivo histórico. Sin embargo, en el caso que nos ocupa y como punto de partida hay una particularidad que ha resultado ser determinante para la actual organización de los archivos militares españoles. Como pone de manifiesto Hermoso de Mendoza, la organización por materias de los fondos documentales y la práctica de hacer "colecciones temáticas" dificulta la localización de los organismos productores de la documentación militar, lo que se constata especialmente en los fondos más antiguos de los archivos de Segovia y Madrid ${ }^{104}$.

Sobre la base de la llegada al alcázar de los fondos del Archivo de Artillería en 1896 para la formación del archivo central, se reclamó documentación que había dispersa en otros depósitos documentales porque -según el Decreto de creación del Archivo General Militar de 1898- conceptualmente ya el Estado había asumido que era imprescindible formar un depósito centralizado de todos los fondos documentales históricos de los ejércitos, y los que la institución continuaba produciendo. Esto lo vemos reflejado en un escrito del Ministro de la Guerra dirigido a la Reina Regente con la propuesta ya cerrada en los siguientes términos:

SEÑORA: Base fundamental de las oficinas del Estado debe ser la perfecta organización de sus archivos, en los cuales han de tenerse cuidadosamente ordenados, a

103 Exposición I Centenario del Archivo General Militar (1898-1998). Segovia, 1-21 de junio de 1998. Folleto de la Exposición.

104 Hermoso de Mendoza, M. ${ }^{\mathrm{a}}$ T.: "Los archivos del Ejército de Tierra", en Los documentos de las instituciones castrenses en el marco de la archivística española: Los archivos históricos Militar, Naval y del Aire. Jornadas de Cultura de Defensa, Cartagena, 2006, p. 87. 
fin de poder encontrar con facilidad cuantos antecedentes y datos sea preciso consultar para el despacho corriente, y en donde metódicamente clasificados se custodien, asimismo aquellos expedientes o documentos que por su valor histórico o estadístico merezcan conservación. Y si esto es de suma importancia en todo departamento ministerial, constituye en el de la Guerra una necesidad cada día mas imperiosamente sentida, puesto que las radicales transformaciones que su organismo ha sufrido en los últimos años, no han podido menos de reflejarse en sus archivos $\ldots{ }^{105}$.

Y acompañando a este documento, el Ministro Miguel Torres envió a la Reina $M^{a}$ Cristina el borrador del Real Decreto que, de inmediato, rubricó. En su artículo primero lo regulaba así:

Se crea un Archivo General Militar, donde se refundirán los archivos dependientes del Ministerio de la Guerra que actualmente existen en Alcalá de Henares, Aranjuez, Guadalajara y Segovia, y en el cual se custodiarán además de todos los expedientes y documentos que merezcan conservarse y no sean de frecuente uso y consulta en los diferentes Archivos de la Administración Central del ramo de Guerra y en los de las Capitanías Generales, Comandancias Generales exentas y Gobiernos Militares... ${ }^{106}$

De esta forma, quedó determinado el principio de procedencia y los objetivos del archivo. El desarrollo de este Decreto de creación se sustanció en el Reglamento de Archivos Militares que, publicado en 1898, ha tenido una vigencia centenaria. A partir de aquí, la documentación consultada tiene que ver con el acondicionamiento de un archivo militar en un edificio histórico que presentaba múltiples dificultades, así como con la dotación con que iba a arrancar la institución. Por cierto que el mobiliario, mesas y otros efectos, incluso alguna estantería, procedían también de los archivos que se clausuraron. En este sentido, resulta curioso comprobar cómo atendían a la compra y montaje acertado de las maderas para los estantes que iban a soportar los legajos. En el pliego de condiciones de la Comandancia de Ingenieros de Madrid para la ejecución de las obras, en el artículo $9^{\circ}$ dedicado a las maderas para las estanterías leemos que "la carpintería de taller será de madera de Balsaín, bien limpia y los tableros y forros de madera de Soria...Las tablas para estantes y forros serán bien limpias y sin nudos..."107

Disquisiciones aparte, lo cierto es que, por el decreto de junio de 1898 de la Reina María Cristina, se ordenaba la instalación en el Alcázar del recién creado Archivo General Militar ${ }^{108}$, gran centro documental de la institución militar que debía centralizar toda la documentación que hasta entonces se conservaba dispersa en los antiguos archivos de Guadalajara, Alcalá de Henares, Aranjuez y diversos archivos específicos

105 A GMS, Sección 2a División 10ª leg. 45.

106 Decreto de creación del Archivo General Militar, dado en Palacio el 22 de junio de 1898 y refrendado también por el Ministro de la Guerra, consultado igualmente en el AGMS.

107 AGMS, sección $2^{a}$, división $10^{\mathrm{a}}$,leg. 46.

108 La referencia al Real Decreto la hemos tomado de la Guía de Archivos Militares Españoles, Madrid, Ministerio de Defensa, 1995. 
o monográficos que dependían del Ministerio de la Guerra ${ }^{109}$. Todos ellos debían unirse a un archivo que ya por entonces acogía la fortaleza segoviana, el del Arma de Artillería, y esperarían la incorporación de la nueva documentación que en un futuro produciría el Ejército español, remitiéndose al Alcázar desde diferentes puntos de nuestra geografía los documentos que se conservaban aún en sus archivos ${ }^{110}$.

La riqueza documental que se conserva en el Alcázar de Segovia, en este Archivo Militar, es difícil de cuantificar y valorar con certeza. Pero ya en el siglo XXI, bien podemos afirmar que éste es el mayor valor patrimonial que guarda la fortaleza segoviana. Como otros importantes archivos pertenecientes a la institución militar, por tanto dependientes del Ministerio de Defensa, está en proceso de catalogación y aunque se conoce su importancia aún queda mucho trabajo en el futuro. También como en el caso de otros centros documentales, bibliográficos o patrimoniales de las Fuerzas Armadas, los fondos han llegado hasta hoy conservados "en perfecta formación militar", con gran celo - muchas veces sin medios-y gracias al trabajo anónimo de aquellos que se han ido sucediendo en los diferentes destinos del Archivo, guiados en el respeto y sentido de la responsabilidad de la custodia de estos miles de legajos, coordinados por los sucesivos Coroneles Directores.

En este sentido, al investigar sobre la formación del archivo militar fue especialmente dura la labor de los militares allí destinados en aquellos primeros años de su formación, a quienes se debe su actual clasificación, de acuerdo con la normativa contemplada en el Reglamento de Archivos Militares de 1898. De hecho, desde 1899 se conservan memoriales de los sucesivos directores del Archivo General Militar exponiendo las condiciones laborales tan penosas con que asumían sus obligaciones, en particular, el frío. A ello se refería descriptivamente el Archivero, primer jefe Florián de Zubizarreta, en un escrito elevado a la superioridad con fecha 26 de noviembre de 1906

...ha tenido que sufrir el personal de esta dependencia las mayores penalidades a causa del frío intensísimo que se siente en el edificio en que se halla instalado este Archivo,....así es público y notorio que se diga en la población que no se comprende cómo se puede resistir el trabajo burocrático el trabajo burocrático a 'pie quieto y a una temperatura BAJO CERO, durante el invierno que es la época de mas duración en esta localidad... ${ }^{111}$.

Como hemos visto, el Real Decreto diseñaba la formación de aquel macroarchivo, pero los acontecimientos políticos aumentaron en septiembre del mismo año el número de legajos que debían llegar al Alcázar, puesto que tan solo tres meses después,

109 Encontramos información y valoración sobre este primer Archivo Histórico Militar de los Ejércitos en ANDrÉs DíAz, R.: "El estado: documentos y archivos", en Artola, M. (dir.): Enciclopedia de Historia de España, Madrid, Alianza Editorial, 1993, capítulo II dedicado a las Fuentes, tomo VII.

110 El primer trabajo que se publicó sobre la historia de este archivo militar fue un artículo de $\mathrm{M}^{\mathrm{a}} \mathrm{d}$. C. DíAz GARRIDO, "Historia de la fundación del Archivo General Militar I y II", Revista de Historia Militar nº 51 (1981) y 52 (1982) respectivamente.

111 Este documento y otros relativos a la fundación del primer Archivo Histórico Militar en el Alcázar de Segovia, su instalación puesta en marcha en aquellos primeros años se conservan en AGMS, Sección $2^{a}$, División $10^{a}$. Esta en concreto se encuentra en el leg. 45. 
por una R.O. de 17 de septiembre de 1898 se dispuso que todos los fondos documentales procedentes de las Capitanías Generales de Cuba, Puerto Rico y Filipinas, se enviaran también al histórico edificio para formar parte del mayor conjunto documental militar reunido hasta entonces.

El primer gran archivo histórico militar, con rango de Archivo General, quedó institucionalizado en junio, pero en otoño de 1898 con carácter de urgencia se anunciaba la llegada de los fondos de Ultramar que debían ingresar en el nuevo Archivo Central Militar en su periodo inicial de formación.

El proceso de creación y formación del Archivo General Militar de España en 1898, vino a coincidir en el tiempo con el fin de la presencia española en América y Oceanía y la repatriación de la documentación de los ejércitos, acreditativa de la presencia militar española en las ya antiguas colonias. Los documentos recalaron en los puertos de Barcelona, La Coruña y Cádiz en diferentes vapores y se articuló su inmediato traslado al archivo segoviano. De esta forma, sin haber previsto nada y con la misma plantilla, los archiveros tuvieron que hacerse cargo de numerosísimas cajas con documentación ultramarina, de sándalo muchas de ellas, que llegaron por ferrocarril a Segovia desde las Capitanías de Cuba, Puerto Rico y Filipinas.

Pero la historia de la formación del AGMS quedaría incompleta y no serviría ya iniciado el siglo XXI al investigador interesado en la historia militar de la Edad Moderna, si no habláramos no solo de la llegada de fondos, sino de la transferencia de documentación a otros centros en diferentes décadas del siglo XX. Ya en 1903 se presentó un problema de asunción de fondos de nuevo acceso al AGMS, no esperado por el personal de archivos que atendía la institución. En enero de aquel año llegaron desde Guadalajara 660 cajas con documentación Y justo al año siguiente, en enero de 1904, el Consejo Supremo de Guerra y Marina envió al alcázar 4302 legajos procedentes de la Escribanía de Cámara, viéndose aún mas desbordados los responsables de la organización del archivo en aquellos sus primeros años.

En cuanto a la salida de documentación del AGMS, mencionaremos brevemente aquellos que lo hicieron, quedando dentro de la misma institución pero en diferente sede. En los años 80 del pasado siglo, se depositaron importantes fondos en el ya consolidado por entonces AGMM. Desde el SHM se entendió que los problemas de espacio en Segovia y el permanente ingreso de nueva documentación podrían condicionar el futuro del AGMS, especializándolo en Expedientes personales, y que otros fondos, se derivaran al Archivo de Madrid. Y así se hizo, de tal manera que pasaron a formar parte del AGMM valiosas series procedentes de Segovia: la sección $6^{\mathrm{a}} / \mathrm{8}^{\mathrm{a}}$, Capitanías, Gobiernos Militares y Ultramar con un total de 1181 legajos; o la sección $2^{\mathrm{a}}$, división $4^{\mathrm{a}}$ sobre Operaciones de Campañas formada por 216 legajos. De igual forma, los fondos documentales de la Sección $7^{\mathrm{a}}$ relativos a la tropa pasaron en 1967 a Guadalajara, procediéndose a su constitución como Archivo General, quedando también custodiados y dependiendo orgánicamente de la misma institución, el SHM, lo que suponía un cambio de ubicación geográfica, pero en ningún caso pérdida de patrimonio documental.

Como ya se avanzó el archivo nació con problemas de espacio endémicos, de difícil solución. No sabemos si vinculado a ellos o no, en los primeros años del siglo XX, 
dos instituciones se interesaron por fondos documentales que ya se habían ido clasificando en el alcázar, el Archivo Histórico Nacional ${ }^{112}$ y la Academia de la Historia. .

En un oficio del Marqués de Polavieja dirigido al entonces Coronel Director del Archivo, Manuel Peñuelas, se le trasladaba el interés de Menéndez Pidal por la documentación que custodiaba el AGMS procedente de la antigua Secretaría de Cámara del Consejo Supremo de Guerra y Marina ${ }^{113}$, proponiendo un trabajo conjunto con personal de los dos archivos para expurgar la documentación histórica y separarla de la administrativa, quedando únicamente ésta última en el archivo militar. El AGMS nombró una Comisión entre los allí destinados para estudiar la petición del AHN que se sustanció en un extenso Indice ${ }^{114}$, ciertamente exquilmante, que fue rechazado de plano por los archiveros militares quienes elevaron una enérgica protesta a la superioridad. A pesar de las negociaciones entabladas y la resistencia del Ejército a ceder todos los fondos solicitados por Menéndez Pidal como Director del AHN, por dos Reales Ordenes de 19 y 26 de septiembre de 1912 respectivamente se reguló la remisión de toda la documentación demandada. Sin embargo, el Coronel Peñuelas presionó y una Real Orden de 12 de septiembre anulaba las dos anteriores y, finalmente solo causaron baja en el alcázar con destino al AHN un total de 193 legajos ${ }^{115}$, montante bastante inferior a la petición inicial que presidió todo este contencioso.

Por su parte, la Academia de la Historia solicitó la entrega de fondos también procedentes del Consejo Supremo de Guerra y Marina, en concreto testamentarías que había que localizar entre los 4802 legajos que lo integraban. En el AGMS tuvieron que realizar ese trabajo de localización, clasificación e indización de los testamentos que resultaron ser un total de 9.240, de los que 191 eran del siglo XVIII ${ }^{116}$ y entre los que se encontraban no solo los de los militares, sino los de sus mujeres en su calidad de aforadas de guerra, pero siempre las seleccionadas eran las de viudas de títulos nobiliarios.

112 Sobre la presencia de fondos militares en otros Archivos españoles, véase Álvarez-Coca GonZÁLEZ, M. ${ }^{a}$ J.: "Fuentes militares e el Archivo Histórico Nacional", en $V$ Jornadas de Archivística Militar. Fuentes Militares en archivos civiles españoles. Madrid, abril (2002), editado en Boletín Asociación Española de Archiveros, Bibliotecarios, Museólogos y Documentalistas, 3, LII (2002), pp.115-153; y Bravo Lledó, P.: "Los documentos del Depósito de la Guerra en el Archivo Histórico Nacional", Boletín informativo. Sistema archivistico de Defensa, 20 (2011), pp. 3-9.

113 AGMS, Sección 2 ${ }^{a}$, División 10 ${ }^{a}$, leg. 47. Carta fechada el 11 de junio de 1913.

114 En el artículo ya citado de M. a del C. Díaz Garrido, en su parte I, se transcribe el Índice completo de toda la documentación solicitada a instancias de Menéndez Pidal, pp. 106-118.

115 AGMS, Sección $2^{a}$, División 10 ${ }^{a}$, leg. 47. En este legajo se conserva la documentación sobre este trasvase de fondos, los índices con los documentos solicitados por Menéndez Pidal y el que por fin reflejaba los fondos que salieron con destino al AHN. Finalmente, en la Guía del Archivo General Militar de Segovia, y a citada, aparece un resumen de los documentos, p. 52; y en el artículo citado en la nota anterior, II Parte, la autora transcribe los que se salvaron del traslado y quedaron en el AGMS, Sección Histórica, pp. 117-124.

116 AGMS, Sección $2^{a}$, División $10^{a}$, leg. 47. En esta misma referencia encontramos también íntegra la lista con la petición de la Academia de la Historia. 


\section{ORGANIZACIÓN DEL ARCHIVO GENERAL MILITAR DE SEGOVIA}

Desde el principio debemos poner de manifiesto las peculiaridades de la organización del archivo histórico militar noventaochista. Su sistematización iba a ser diferentes a los otros depósitos documentales militares que ya existían con anterioridad, siempre menores desde el punto de vista cuantitativo. La estructura y articulación del primer archivo histórico militar quedó reflejada en el ya citado Reglamento de Archivos Militares de 1898 que ha permanecido vigente cien años hasta la conmemoración del Centenario, momento en que entró en vigor el de 1998, fruto del trabajo de un equipo facultativo y del buen hacer de su inspirador y coordinador, Antonio González Quintana.

Desde su etapa fundacional, la documentación procedente de los organismos e instituciones del ramo de Guerra en diferentes momentos históricos, se distribuiría en el Archivo General Militar de Segovia entre nueve secciones definidas con criterios temáticos, es decir, por materias; y cada una de ellas se encontraba estructurada en un variable número de divisiones. Los fondos tienen su origen en organismos productores, el sistema de Consejos con los Austrias y a partir del reinado de Felipe V, el Consejo del Despacho Universal y su Secretaría de Despacho, donde se nombró un Secretario exclusivamente para atender todo lo relacionado con Guerra. Desde 1705, la Secretaría se escinde en dos, una de ellas sería la importante Secretaría de Despacho de Guerra y Hacienda, dos ramos de la administración con suficiente empaque como para contar con una sola Secretaría para cada uno de ellos, así desde 1714 se constituyó en Secretaría de Despacho de Guerra que también asumió competencias por razones evidentes, de Marina y Ultramar pero únicamente hasta 1721.

Las reformas militares de los Borbones culminaron con la edición de las Ordenanzas Generales de Carlos III en $1768^{117}$, sin embargo no afectaron ni modificaron la Secretaria ni sus procedimientos, de ahí que para toda la investigación en Historia Militar de la Edad Moderna se tengan perfectamente definidos los órganos productores de la documentación. Cabe recordar que no solo la Secretaría del Despacho, sino que -como figura en el decreto de creación del archivo (1898)- las armas y los cuerpos facultativos del Ejército estructuradas en inspecciones o direcciones generales -según el momento histórico- tenían un grado de autonomía en sus actividades que queda reflejado en la ingente producción documental de cada una de ellas que contaba con su propio depósito documental. La única novedad en este sentido aparece en plena Guerra de la Independencia cuando se institucionaliza por fin en el organigrama de los Ejércitos el Cuerpo de Estado Mayor, uniéndose a la Secretaría de Guerra, considerándose su fundador al General Blake y Joyes ${ }^{118}$.

117 Ordenanzas de S.M. para el Régimen, disciplina, subordinación y servicios de sus Exércitos. Madrid, Oficina de Antonio Marín, 1768. 2 vol.

118 En nuestro "Estudio Preliminar" sobre la figura de Joaquín Blake, en Herrero Fernández-QueSADA, Macía Martín, y Martínez Cortés, op. cit. (n. 36), pp. 17-56. 
CUADRO ORGÁNICO (1898)

\begin{tabular}{|l|l|}
\hline${\text { SECCION } 1^{\mathrm{a}}}^{\mathrm{a}}$ & PERSONAL \\
\hline SECCION $2^{\mathrm{a}}$ & ASUNTOS \\
\hline SECCION $3^{\mathrm{a}}$ & MATERIAL \\
\hline SECCION $4^{\mathrm{o}}$ & ULTRAMAR \\
\hline SECCION $5^{\mathrm{a}}$ & $\begin{array}{l}\text { ASUNTOS DEL CONSEJO SUPREMO MILITAR, JUNTA CONSULTUVA } \\
\text { DE GUERRA Y VICARIATO GENERAL CASTRENSE }\end{array}$ \\
\hline SECCION $6^{\mathrm{a}}$ & $\begin{array}{l}\text { FONDOS DE LAS CAPITANIAS GENERALES, SUBINSPECCIONES, } \\
\text { GOBIERNOS, Y COMANDANCIAS MILITARES }\end{array}$ \\
\hline SECCION 7 & DCUMENTACION DE TROPA Y CAJAS DE RECLUTA \\
\hline SECCION $8^{\mathrm{a}}$ & $\begin{array}{l}\text { FONDOS PROCEDENTES DE LA CAJA GENERAL DE ULTRAMAR Y } \\
\text { DEPÓSITO DE BANDERA Y EMBARQUE }\end{array}$ \\
\hline SECCION $9^{\mathrm{a}}$ & JUSTICIA. CAUSAS, PLEITOS, SUMARIAS, TESTAMENTARIAS \\
\hline
\end{tabular}

Según el Reglamento de Archivos de 1898, el AGMS se iba a organizar en estas nueve secciones, con sus correspondientes divisiones internas de desigual número en unas o en otras. De entrada es importante recordar que algunas de ellas no se llegaron a formar, como la $4^{\mathrm{a}}$ que iba a ser destinada a la ordenación de Pagos e Intervención General de Guerra, Intendencias Militares y Comisarías. Lo mismo ocurrió con la $5^{\mathrm{a}}$ sección que se tenía previsto constituir con fondos documentales del Consejo Supremo de Guerra y Marina, Junta Consultiva de Guerra y Vicariato General Castrense, tampoco se constituyó nunca.

Entre estas incidencias orgánicas que modifican la declaración de intenciones del Reglamento de 1898, también hay que señalar la fusión de las secciones $6^{\mathrm{a}}$ y $8^{\mathrm{a}}$, aunque en la actualidad una parte de esta documentación está en depósito en el AGMM, de la misma forma que la $4^{\mathrm{a}}$ sección de la $2^{\mathrm{a}}$ División, campañas.

En este trabajo trataremos las secciones que se pueden consultar en el Archivo Militar de Segovia, de interés para la investigación en historia militar de la Edad Moderna, en base a una selección inevitablemente personal de ciertas subseries.

\subsection{SECCIÓN PRIMERA. PERSONAL. LOS EXPEDIENTES PERSONALES}

La más conocida y consultada del Archivo General Militar es la primera sección, verdaderamente su corpus documental más identificativo y, sobre todo, la de mayor volumen, puesto que según un dato aportado por quien fue su Director el Coronel Vázquez Gimeno, en 1999 superaba los sesenta y siete mil legajos ${ }^{119}$.

La primera subserie de esta sección es la formada por los Expedientes Personales Profesionales, integrada por los denominados Expedientes Personales de los militares españoles, verdaderos dossiers profesionales, que en parte fue publicada en nueve volúmenes por el Consejo Superior de Investigaciones Científicas, Hidalguía, en la década de los cincuenta con un criterio excluyente, puesto que al priorizar la documentación que aportaba información para el estudio de la genealogía, los expe-

119 VÁzQuez Gimeno, op. cit. (n. 32). 
dientes de militares sin aquella, quedaron fuera del Catálogo. Además y no solo por ello, estamos ante una catalogación incompleta porque después no ha continuado la edición, y como el AGMS es un centro documental vivo, desde los sesenta se han ido incorporando nuevos y numerosísimos expedientes ${ }^{120}$

Sin duda, los archivos militares tienen una documentación específica, la generada por la institución militar, que ofrece una información exhaustiva y, en ocasiones, sorprendente, lo que se constata especialmente en los fondos documentales de esta primera sección del archivo. Los expedientes personales contienen información profesional y personal sobre Generales, Jefes, Oficiales, Suboficiales y personal civil que han servido en los ejércitos y en la Administración del ramo de la Guerra a lo largo de nuestra historia. Son unidades documentales muy características de la institución militar que encontramos en los archivos históricos de los ejércitos, entre sus fondos documentales y, sin duda, una feraz tipología documental que constituye uno de los conjuntos de fuentes mas importantes del patrimonio histórico-militar. Todos ellos, se fueron reuniendo en el Archivo General Militar de Segovia desde 1898. Aquí debemos recordar de nuevo que aunque los expedientes y documentación de la tropa estuvieron durante muchos años en el alcázar segoviano, por razones fundamentalmente de espacio fueron trasladados todos ellos en la década de los años setenta del pasado siglo al Archivo General Militar de Guadalajara, fundado en 1967. Esto no impide que, en medio de nuestras investigaciones sobre legajos que contienen expedientes personales en Segovia, los historiadores no nos los encontremos trufados entre los de los oficiales o Generales, apareciendo algunos que pertenecieron a la clase de tropa. Sin embargo, lo cierto es que solo son las excepciones que confirman la regla.

Según los datos que ofrece la Guía más reciente del propio Archivo ${ }^{121}$ se han contabilizado alrededor de 44.515 legajos de expedientes personales, clasificados alfabéticamente como se estableció en el Reglamento de Archivos Militares de 1898, mandando como criterio prioritario para su ordenación el primer apellido del militar, aunque esta clasificación alfabética presenta algunas excepciones significativas. ${ }^{122}$ La Primera Sección del AGMS que custodia todos estos expedientes profesionales de militares se estructura en una colección y algunas subseries que no incluimos exhaustivamente en este trabajo porque para el acceso del historiador a estos legajos no aporta nada ni es relevante y tiene únicamente interés para los técnicos ${ }^{123}$. La praxis nos permite afirmar que el investigador con los apellidos, cronología profesional y

120 Catálogo de los Expedientes personales del AGMS.... Madrid, Instituto Salazar-Castro CSIC, 19581962, 9 volúmenes.

121 VÁzquez Montón, J. I.: Guía del Archivo General Militar de Segovia, Madrid, Ministerio de Defensa, 1997.

122 Según los datos que figuran en la Guía citada en la nota anterior, la G siempre es "j" seguida de "e" o de "i"; la H no existe ni al principio y al final de los apellidos; la K es "Ke" y "Ki" como "Q", y como "C" en el resto de casos; la V tampoco existe y es siempre "B", la W al principio del apellido es siempre "U"; la X al principio del vocablo es "J", "CS" en el medio, y "Z" al final; la Y seguida de vocal es "LL", e "i" en el resto de los casos. Y, finalmente, la "Z" después de las vocales "e" e "i" siempre es "C".

123 Esta clasificación interna y las subseries aparecen perfectamente reflejadas en la Guía que citamos en la nota anterior. De igual forma, se hace referencia, aunque menos prolija, en GonZÁLEZ, M. ${ }^{a}$ del M.: "Fondos contemporáneos en el Archivo General Militar de Segovia”, Revista de Historia Militar, número extraordinario dedicado a la Historia militar: métodos y recursos de investigación, Madrid, IHCM, 2002, p. 400. 
vital del militar y arma o cuerpo en el que sirvió, será perfectamente atendido por el personal de sala del AGMS.

Por su importancia como fuentes para el estudio de la historia militar en la Edad Moderna, alguna de las citadas subseries -como Célebres tendrán un espacio en estas páginas; así como fondos con una entidad e idiosincrasia documental propia que hace que formen, siempre dentro de esta primera sección; Nos referimos en concreto a series monográficas de documentación en función de su específica tipología-como los Expedientes Matrimoniales-; o de su procedencia por el organismo productor - como los Expedientes de pensiones, retiros y pagas de toca- generados como consecuencia de la institucionalización del Montepío Militar en el reinado de Carlos III.

Las fechas extremas que se manejan en la Primera Sección del AGMS cubren el arco cronológico del siglo XV al XX, aunque cuantitativamente hay una desigualdad en su representación dentro de los fondos de esta sección del AGMS. Los expedientes de militares profesionales más antiguos son de principios del siglo XVI, y como exponente de las fuentes militares para el estudio de la historia moderna no podemos dejar de mencionar en este trabajo el que hasta el día de hoy se ha considerado primer expediente personal, fechado en 1619 correspondiente a D. Rodrigo Calderón Landelín ${ }^{124}$, noble, hijo de un oficial y que llegó a ser secretario de la cámara del rey. En este legajo, se conserva un pequeño cuaderno de veinte páginas manuscritas en el anverso y reverso intitulado "Nacimiento, vida, prisión y muerte de D. Rodrigo Calderón, Marqués de Siete Iglesias, Conde de la Oliva".

Sin embargo, desde el punto de vista cuantitativo, la presencia en la Primera Sección del AGMS de legajos conteniendo Expedientes Personales de militares del XVIII es ciertamente abrumadora. La llegada de la dinastía Borbón en el arranque del siglo, puso en marcha un vertiginoso proceso de reorganización militar con la edición de sucesivas Ordenanzas y Reglamentos que se sustanció en el diseño de un nuevo modelo militar en el que se crearon los Reales Ejércitos Permanentes al servicio de la Monarquía, la adopción del Regimiento como unidad clave para la organización de las tropas, la estructuración renovada de las históricas armas, la integración definitiva dentro del nuevo organigrama de los llamados Cuerpos Facultativos, Ingenieros y Artillería y tan importante como esto, la definitiva institucionalización de la enseñanza militar ilustrada con la fundación de colegios y academias para la formación de los ingenieros militares y los oficiales de artillería, proceso en el que cobra relevancia el Real Colegio de Artillería de Segovia que acuñó un nuevo modelo de centro docente científico-militar ${ }^{125}$.

Y fue en aquel contexto histórico, con la implementación del nuevo modelo militar borbónico cuando se generalizó ya con carácter obligatorio la formación de Expedientes Personales de los militares con la inclusión de las sucesivas Hojas de Servicio que se les abrieron desde su ingreso en los Ejército hasta su retiro o fallecimiento.

\footnotetext{
124 Resulta de cita obligada al referenciar documentación sobre este personaje "célebre", la excelente biografía de Martínez Hernández, S.: Rodrigo Calderón, la sombra del valido. Privanza, favor y corrupción en la Corte de Felipe III, Madrid, Marcial Pons, 2009.

125 Sobre ello hemos publicados diferentes trabajos, ya citados en notas anteriores, incluido el último que está en prensa.
} 
Dentro de las fuentes específicas de los archivos militares, el Expediente Personal como unidad documental cobra especial relevancia por la cantidad y calidad de la información que condensan. En cada uno de ellos, aparece reunida toda la documentación oficial generada a lo largo de la vida profesional del militar, lo que implica que se encuentre en ellos una gran variedad documental: Reales Despachos con sus sucesivos ascensos, Hojas de Servicio, expedientes matrimoniales, documentos acreditativos de la calidad de noble o limpieza de sangre para ingresar en los ejércitos ${ }^{126}$, reclamaciones de haberes, pasaportes militares (habitualmente ornados con una espléndida heráldica), memoriales de intervención en campañas o de participación en las llamadas "comisiones facultativas" de diferente tenor (científicas, diplomáticas, políticas, culturales y patrimoniales, de espionaje industrial por Europa...), concesión de condecoraciones con su pormenorizada documentación justificativa, licencias concedidas por asuntos personales o de salud para reponerse siguiendo tratamientos específicos con la toma de aguas o baños, intervención en expediciones científicas multidisciplinares ${ }^{127}$, acreditación de miembros de las diferentes Reales Academias o Sociedades Eruditas de Amigos del País, traducciones de obras extranjeras al castellano por los oficiales, producción intelectual y bibliográfica reconocida ${ }^{128}$.

Esta tipología documental seriada de los militares del XVIII ha permitido a los historiadores modernistas trabajar no solo en notables individualidades, militares y Generales destacados en el ámbito castrense, coincidiendo con un proceso de regeneración historiográfica del género biográfico ${ }^{129}$, sino también renovar desde planteamientos metodológicos contemporáneos, el conocimiento de la institución militar en su conjunto, en su orgánica, en sus procedimientos específicos ${ }^{130} \mathrm{e}$, indiscutiblemente, en el estudio de amplio campo de competencias de las autoridades militares y Capitanes Generales en las España Ilustrada ${ }^{131}$, y en un aspecto tan importante como desconocido, la financiación de la guerra ${ }^{132}$. Pero además, con la vuelta a estas fuentes primarias por parte de los investigadores, se ha dinamizado la historia social de

126 En este sentido no debemos crear falsas expectativas, ya que estos Expedientes acreditativos de la buena cuna, se encuentran escasamente en los legajos de los Expedientes Personales de los militares porque debían presentarlos en la Unidad a la que deseaban pertenecer o al Colegio Militar en el que aspiraban a formarse, pasando a formar parte de los archivos propios de esas instituciones. Sin embargo, parte de estos documentos se conservan en los expedientes matrimoniales de los militares, de los que mas tarde se tratará en este artículo, especialmente partidas de bautismo y documentación propia de los registros parroquiales que ayudaban a reconstruir los orígenes y la arquitectura familiar del oficial, remontándose cuando menos a dos generaciones anteriores.

127 Herrero Fernández-Quesada, op. cit. (n. 85), pp. 831-858.

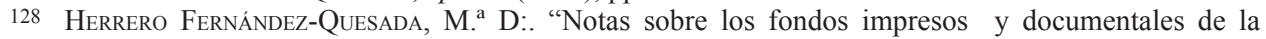
Biblioteca de la Academia de Artillería y el Archivo General Militar", Estudios Segovianos, 94, tomo XXXVII, Segovia, Instituto Diego de Colmenares, Diputación de Segovia, CSIC, 1996, pp. 349-388.

129 Herrero FernándeZ-Quesada, op. cit. (n. 84).

130 Cepeda Gómez, J.: "La época de Carlos IV: crisis del Ejército Real Borbónico", en Fuerzas Armadas Españolas, Madrid, 1985, tomo II.; y "El Ejército de Carlos IV”, en Aproximación a la historia militar de España. Madrid, Ministerio de Defensa, 2006, vol. I, pp. 351-362

131 Andúuar Castillo, F.: “Capitanes generales y capitanías generales en el siglo XVIII", Revista de Historia Moderna. Anales de la Universidad de Alicante, 22 (2004), pp. 7-78.

132 En notas anteriores ya se citó la obra Yun CASAlilla: op. cit. (n. 71), y otras de AndúJar Castillo, aunque aquí queremos recordar El sonido del dinero, op. cit. (n. 70). 
los ejércitos borbónicos ${ }^{133}$, con la realización de estudios prosopográficos de los que tenemos testimonios relevantes, de la misma forma que en las dos últimas décadas los Expedientes Personales de los militares españoles se han constituido en valiosas herramientas documentales de obligada consulta para el estudio de las élites y las redes sociales en el siglo XVIII ${ }^{134}$.

\subsection{SUBSERIE DE CÉLEBRES}

En este trabajo, dedicaremos un espacio monográfico a una de las subseries más conocidas del AGMS. Dentro de su Primera Sección, con el paso del tiempo, la consulta por parte de los investigadores y el mayor conocimiento y familiaridad con los fondos de los archiveros militares, derivados de sus trabajos de ordenación, catalogación y sistematización de los fondos, emergió naturalmente una subserie de Expedientes Personales de militares que, en primera instancia, fue considerada como de hombres "Ilustres" destacados en la historia no solo militar, sino de España, hasta que finalizando el siglo pasado se optó por la denominación de "célebres". A lo largo de los años, se fueron seleccionando entre los expedientes personales de la primera sección e incorporándose a la llamada Sección Histórica del Archivo, totalizándose 99 legajos que integran 1.655 expedientes personales de militares célebres, siendo el organismo productor de estas fuentes que interesan para el estudio de la historia militar en la Edad Moderna, mayoritariamente la Secretaría del Despacho de Guerra. Entre ellos, también hay registros de documentación en expedientes de personajes históricos ajenos al universo castrense.

En los Expedientes de Célebres anteriores al siglo XVIII los contenidos varían no solo cuantitativamente -algunos son poco voluminosos- sino también de forma cualitativa, incorporando una serie de documentos variados como memoriales de consultas al Consejo, Reales Cédulas, ascensos, breves perfiles biográficos manuscritos, y documentos que aportaban la acreditación de méritos no solo de aquellos militares sino también de sus antepasados. Ese es el caso del documento que aún a día de hoy es el mas antiguo que conserva el AGMS. Se trata de una carta de los Reyes Católicos perdonando a Juan de Cárdenas fechada en Toledo en 1477 y que se encuentra integrada en su Expediente ${ }^{135}$.

Así, encontramos legajos con documentación personal y profesional de personas reales, como el Expediente Personal de Felipe V, de militares que fueron políticos y también diplomáticos como demuestra el abultado expediente del Conde de Aranda, Secretarios del Despacho Universal o de la Guerra, de Ministros de la Guerra en buen número como el José Carrillo de Albornoz, Duque de Montemar (fechas extremas 1683-1748) o el de José $\mathrm{M}^{\mathrm{a}}$ Carvajal y Urrutia (fechas extremas 1763-1832), además de Ministros de la Marina, Fomento o Estado (muchos de estos ya del XIX). De la misma forma, cuentan con expediente personal en Célebres miembros de Casas Rea-

133 AndúJar Castillo: op. cit. (n. 58).

134 Imízcoz BeunzA, J. M. a: "El capital relacional. Relaciones privilegiadas y redes de influencia en el Estado español del siglo XVIII", en Imízcoz BeunZA, J. M. a y OLIVIERI, O. (eds.): Economía doméstica y redes sociales en el Antiguo Régimen, Madrid, Sílex, 2010, pp. 227-281.

135 AGMS, Sección 1', Célebres, caja 26, exp. 11. 
les Europeas que han sido distinguidos con honores o títulos honoríficos de los Ejércitos, Virreyes como Joaquín de la Pezuela penúltimo del Perú, Capitanes Generales como Francisco del Castillo Fajardo, Marqués de Villadarias y Capitán General de la Artillería en Flandes y Valencia respectivamente (fechas extremas 1690-1713), Tenientes Generales como José M. ${ }^{a}$ Cienfuegos y Jovellanos, Capitán General de Cuba y Ministro de la Guerra (fechas extremas 1777-1829), innumerables Generales, Gobernadores Militares, Urbanistas, Arquitectos-Ingenieros Militares, altas jerarquías de la Iglesia vinculadas puntualmente a los ejércitos, Inquisidores Generales como Ramón Josef de Arce, Patriarca de las Indias (fechas extremas 1806-1808), hombres de letras que aunaron a esta su condición de militares como el escritor y oficial José Cadalso, o, por finalizar, personajes vinculados a actividades en principio distantes de las castrenses como el expediente que se conserva en esta Subsección del pintor Diego Velázquez.

Afortunadamente, Célebres tiene publicado un Catálogo que fue realizado por el Director del Archivo, Coronel Gregorio Vázquez Gimeno en los últimos años del siglo $\mathrm{XX}^{136}$, instrumento que facilita la búsqueda y localización sobremanera. Pero además, y en atención a que esta Subsección presenta una gran demanda de consulta por parte de los investigadores, está digitalizada y así se ofrece al investigador en el archivo segoviano, aunque para facilitar su consulta se puede acceder a una copia en el IHCM en Madrid. Este servicio además, se entiende que garantiza la mejor conservación de estas fuentes documentales en soporte papel.

De todos los Expedientes Personales de la Subsección de Célebres nos hemos permitido referenciar tan solo algunos de ellos, con el fin de orientar al investigador en historia militar de la Edad Moderna. Entre los del siglo XVII se encuentran el de Fernán Arias de Saavedra, Capitán General de toda la Artillería (fechas extremas 1632); el de Francisco Antonio de Agurto, Marqués de Gastañaga (fechas extremas 16381689); el del Capitán General Guillermo Bete, Marqués de Lede (fechas extremas 1645); el del Duque de Arschot, Capitán General de la Armada de Flandes (fechas extremas 1660); el del Gobernador de Gante Pedro Álvarez Vega, Conde de Grajal Castellano, que fue Capitán General de Artillería (fechas extremas 1690-1694); el del Maestre de Campo de Infantería Pedro de Alcántara (fechas extremas 1695); o, por finalizar, el expediente de Juan José de Austria, Gobernador General de todas las Armadas Marítimas (fechas extremas 1647).

En el conjunto documental de expedientes personales de militares célebres del siglo XVIII, la mención sería extensa y prolija, lo que no permiten los límites establecidos para la extensión de nuestro trabajo, pero cabría mencionar aquí los del Marqués de la Ensenada, el Ministro Caballero, Manuel Godoy, Próspero Verboom, Conde

136 VÁzQuez Gimeno: op. cit. (n. 32). Este catálogo se dividió en dos partes para su publicación, como se explica en la introducción a la edición. La primera está formada por los asientos descriptivos de los expedientes de Célebres, y en la segunda se incluyen tres útiles índices: el primero es alfabético con indicación de la página donde se encuentra en el catálogo ya que la ordenación de estos fondos documentales es topográfica mas que alfabética. El segundo índice ofrece el número de caja y expediente, es decir, la localización topográfica del legajo en el archivo. Y, finalmente el tercero incluye gran número de títulos nobiliarios que, en ocasiones, permiten llegar al expediente del militar que no fue registrado de entrada en el archivo por su apellido y nombre sino por su título nobiliario. 
de Gazola, Vicente Alcalá Galiano, Vicente Gutiérrez de los Ríos, Pedro de Lucuce, García de la Huerta, Agustín de Bethancourt, Martín García Loygorry, Joaquín de la Pezuela, Tomás de Morla, Marqués de las Amarillas, Cienfuegos y Jovellanos, etc.

\subsection{SERIE DE EXPEDIENTES MATRIMONIALES}

Igualmente por su contenido documental para el estudio de la historia moderna, en particular del siglo XVIII, reviste interés dentro de la primera sección del AGMS, la serie de Expedientes Matrimoniales instruidos a militares y marinos entre 1761 y 1865. Para investigar sobre esta serie, desde 1959 se cuenta con una valiosa herramienta de localización, publicada por Enrique de Ocerín ${ }^{137}$ quien optó por una clasificación y ordenación alfabética de los expedientes pero de las aspirantes a esposas de los oficiales, porque en efecto eran "la esencia de la documentación" y las pruebas se referían a ellas, que aportaban para el proceso de investigación de su idoneidad todos los documentos acreditativos necesarios, con antecedentes de, por lo menos, dos generaciones anteriores.

La serie de Expedientes Matrimoniales presenta una dificultad en su localización y consulta puesto que con anterioridad al inicio de la catalogación mencionada, en el archivo se comenzó un trabajo de integración de estos legajos en los expedientes personales de los militares - sin un criterio demasiado elaborado y meditado-, mas o menos un $40 \%$ de los legajos que componían el fondo, dispersando así los expedientes matrimoniales anteriormente reunidos. Ocerín realizó como punto de partida de su trabajo un Índice de los expedientes matrimoniales que no se habían fusionado con los personales, no solo por falta de tiempo y de medios, sino porque muchos de ellos por su volumen documental y medidas (tamaño A4) no podían plegarse para adaptarse al formato de los expedientes personales de los militares que siempre se archivaron en un tamaño aproximado a la cuartilla. Con el tiempo, los expedientes matrimoniales que sobrevivieron a aquel proceso de fusión documental, fueron depositados todos ellos en el Archivo como "incidencias". ${ }^{138}$

La instrucción de los Expedientes Matrimoniales a la oficialidad de los Ejércitos, está relacionada con la iniciativa emprendida en el reinado de Carlos III para la creación del llamado Montepío Militar. La incoación obligatoria de Expedientes Matrimoniales para que los oficiales y jefes pudieran casarse, pone de manifiesto la mayor fiscalización o intervención del poder del Estado en el siglo XVIII en los matrimonios de los militares, fundamentalmente como consecuencia de los filtros establecidos para el acceso a la milicia, arbitrados por los Borbones como estrategia de atracción de los jóvenes de la nobleza a la profesión castrense y con el fin de mejorar la imagen pública de la institución castrense en claro proceso de deterioro en

137 Ocerín y García de Llamera, op. cit. (n. 33). Esta obra nacía con vocación de continuidad en tomos de publicación posterior que no llegaron a editarse, con una previsión a priori de hacer entre cuarenta y cincuenta mil asientos o fichas de cada expediente matrimonial. En el primer tomo se registraron 5375 asientos ordenados alfabéticamente por los apellidos de las señoras aspirantes a casarse. La serie no está catalogada completa y aunque en ambos tomos no aparezca un determinado expediente matrimonial eso no quiere decir que no se encuentre entre los anaqueles del AGMS.

138 Esta información se detalle en la introducción a su Catálogo ya citado, tomo I, p. XLIX. 
las últimas décadas de la centuria anterior. Es por ello que para la concesión de las licencias matrimoniales, se exigía a las futuras consortes demostración de su "calidad" para que, sin desdoro, los hijos también pudieran en un futuro seguir la carrera de las armas. Las probanzas se verificaban en el Consejo de Guerra y Marina, órgano de procedencia de esta serie de Expedientes Matrimoniales del AGMS, desde el que se emitía finalmente la Real Licencia si procedía. Como cierre de la fase burocrática de este tipo de instrucciones, se archivaban todos los expedientes matrimoniales con miras no solo a la consignación de la dote, sino -y más importante- al cobro de subsidios por fallecimientos.

Ciertamente, esas fueron las razones fundamentales para proceder a iniciar las incoaciones de estos expedientes para la obtención de licencias matrimoniales para militares y marinos en el siglo XVIII, cuya formalización quedó reglada definitivamente desde $1761^{139}$. La obligatoriedad de estos trámites trascendía los límites geográficos de la Península y entre estos fondos encontramos que oficiales destinados en $\mathrm{La}$ Florida, La Luisiana, La Carolina, América, y Filipinas también debían cumplir con la burocracia establecida para contraer matrimonio. Sin embargo a aquellos militares - con el fin de no dilatar los trámites en extremo- una vez presentados los expedientes matrimoniales, los Virreyes y Capitanes Generales estaban facultados para concederles licencias provisionales que finalmente serían ratificadas en Madrid por el Consejo de Guerra y Marina para que tuviese efecto en el Montepío. De ahí que -como pudo comprobar Ocerín- en ocasiones se cuente con dos o más copias realizadas y enviadas por separado para evitar el extravío de la documentación ${ }^{140}$, denominándoseles "primera vía", "segunda vía" o "tercera vía".

Las aspirantes a esposas de oficial debían probar nobleza en caso de tenerla acreditada, legitimidad y limpieza de sangre de su primer apellido; y del materno, limpieza y legitimidad. Únicamente quedaban exentas de justificarlo por vía paterna, las hijas de militares del grado de capitán en adelante teniendo que aportar el despacho de concesión del empleo del padre. Además, en la normativa se llegó a contemplar la posibilidad de admitir mujeres del Estado Llano, ajustando bien los límites, y siempre que sus padres fueran

hombres buenos, honrados, y limpios de sangre, y oficios, debiendo excluirse absolutamente todas aquellas cuyos padres o abuelos inmediatos exercieron, o hayan exercido empleos o profesiones mecánicas o populares; y las hijas o nietas de artistas y las de los mercaderes, cuando éstos no sean de razón o de cambios ${ }^{141}$.

No obstante, en la praxis se aceptaban algunas señoras "honradas", siempre de acreditada "buena conducta", pero en este supuesto exigiéndoseles para su admisión

139 GIL MuÑoz, M.: "Aproximación al estudio de la vida familiar de los militares españoles (siglo XVIII), Revista de Historia Militar, 96 (2004), pp. 99-146

140 En la introducción al tomo I del Catálogo ya citado, p. XLVII, escrita también por Enrique Ocerín.

141 La regulación de toda la normativa de instrucción de expedientes matrimoniales, requisitos, proceso y procedimientos así como obtención de las Reales Licencias, se encuentra en el Reglamento de la fundación y establecimiento del Monte Pío Militar, Madrid, Imp. Real, 1761, Este texto fue reformado y actualizado en enero de 1796. 
una dote muy superior a las anteriores. En el título IV del Reglamento del Montepio se explica con claridad:

aunque las mujeres que quieran casarse con Oficiales, han de ser precisamente de las calidades que se han declarado en el Artículo antecedente; no obstante, para que en los matrimonios que contraxeren, concurra también alguna decente, y de regular conveniencia; es nuestra Real voluntad, que las Nobles, y Hidalgas de origen han de llevar veinte mil reales de vellón de dote, y las del Estado Llano cinquenta mil reales, sin que se deban admitir sin dote mas que a las hijas de los Oficiales, y Ministros de la Guerra de las clases que se han comprehendido en las contribuciones del Monte... ${ }^{142}$.

Sin embargo, sirva como dato orientativo, la ponderación que hizo Océrin sobre todos los expedientes catalogados en su obra, quien apuntaba que un cincuenta por ciento de las señoras que solicitaban la Real Licencia de Matrimonio, acreditaron su Nobleza.

En cualquier caso, tanto unas aspirantes como otras debían depositar su dote para poder contraer el matrimonio aunque como hemos visto, de diferente cuantía en función de su extracción social, dote que no necesariamente debían aportar en metálico, resultando igualmente válido el aval por medio de propiedades, tierras, bienes inmuebles... Los documentos acreditativos de estos títulos de propiedad se elevarían con el resto del expediente al Secretario de Estado y del Despacho de la Guerra para su supervisión, debiendo ${ }^{143}$ "poner el mayor cuidado, y vigilancia, en averiguar bien y fielmente, por todos los medios posibles, la legitimidad de los mencionados documentos, porque han de ser responsables de cualquiera descuido u omisión, que en esta parte tuvieren, y sujetos a la pena impuesta en la Ordenanza..."

No se dejó ningún supuesto sin contemplar en la normativa y para el caso de oficiales que desearan casarse con mujeres extranjeras -que no era infrecuente en los destinados en Ultramar- el procedimiento se reguló como sigue ${ }^{144}$ :

De las reglas que quedan prevenidas no se ha de exceptuar mujer alguna. Las que no sean nativas, o bien oriundas de nuestros Reynos y Dominios, deben justificar la calidad de su origen, y nacimiento con Despachos de los Tribunales, Senados o Parlamentos establecidos en las Ciudades cabezas del reyno, o Provincia de donde fueren, o derive la mujer: de manera que dichos documentos han de ser expedidos en debida, y auténtica forma, y con todos los requisitos que justifiquen plenamente la legitimidad de ellos, según la práctica, y estilo de los Magistrados, por donde fueron despachados.

Con este marco legislativo se instruyeron desde principios del reinado de Carlos III los expedientes matrimoniales para obtener Real Licencia de casamiento, y siguiendo puntillosamente todo lo contemplado en el Reglamento, el investigador encuentra en este fondo documental una suerte de "caja de pandora", en nuestra opinión, aún por abrir debidamente para el estudio de la historia de los militares dieciochescos y el entramado de su núcleo y entorno familiar. Por la documentación requerida suelen

142 Del título IV del Reglamento citado en la nota anterior.

143 Este procedimiento queda explicitado en el título VII del mismo texto.

144 Del Título VI del mencionado Reglamento. 
ser abultados legajos con toda la documentación acreditativa, especialmente de la mujer que solía presentar antecedentes de varias generaciones y, en algunos de ellos, con inclusión de árbol genealógico. Precisamente es por ello que, aunque son fuentes poco trabajadas en investigaciones de historia militar de la edad moderna, si se han acercado a ellas aquellos que tienen interés por la genealogía histórica ${ }^{145}$. No cabe duda que desde esa perspectiva planteó Enrique de Ocerín su minucioso inventario de los expedientes matrimoniales de las aspirantes, quien enfatizó el extraordinario valor de este fondo "en sus aspectos genealógico, nobiliario y familiar" 146 .

$\mathrm{Su}$ Catálogo sobre esta serie de Expedientes Matrimoniales ha permitido poner de manifiesto que frente a la norma más generalizada de aportar documentos acreditativos de dos generaciones, la excepción se confirma en las señoras vascas que siempre presentaban las pruebas de nobleza de sus cuatro apellidos, sin que se exigiera en ningún caso. Sin embargo, con el tiempo, conceptual y consuetudinariamente el nivel de exigencia fue cambiando, siendo más flexibles en la exigencia de nobleza o limpieza de sangre, encontrándose en el AGMS numerosos expedientes que lo refrendan, pues en la consulta se constata tan solo que las candidatas a esposas habían acreditado ser de "apreciables y loables circunstancias", de "arreglada conducta", de "buena vida y buenas costumbres, de "estimables prendas y condiciones", de "sanos principios de moralidad" o de "acrisolada conducta moral y política"... sin referencias expresas a la calidad.

Estos fondos documentales han llegado hasta aquí por el procedimiento reglado de la Administración Militar de archivarlos junto al Expediente Personal del militar, con miras a la consignación de la dote que debía aportar cada candidata y al cobro de ayudas y subsidios por parte de los herederos, siendo verificadas las probanzas de forma definitiva en el Consejo Supremo de Guerra y Marina. La naturaleza de la documentación acreditativa de la aspirante a esposa de oficial nos sitúa ante un trabajo de investigación intuimos que motivador, aún por abordar, que permitirá arrojar luz sobre la invisibilidad de la esposa del militar que, como la mayoría de las mujeres de la época no dejaban huella de su presencia en el ámbito público y quedaban confinadas a la retaguardia del hogar.

A pesar de la consolidación desde hace varias décadas de la historia de las mujeres y de las relaciones de género, como línea historiográfica con nutrida producción $^{147}$, poco o casi nada sabemos de aquellas mujeres que debían dar un perfil determinado para contraer esponsales con militares. Pero -gracias al criterio de

145 Borrero y de Roldán, F. L.: Índice genealógico de los oficiales del Real Colegio de Artillería y matrimonios de los mismos (1765-1808), Madrid, Real Consejo de Ordenes Militares-IHCM, 2005,2 volúmenes.

146 Ocerín y García de Llamera, op. cit. (n. 33), tomo I, introducción del autor al catálogo, p. XLVI.

147 Como Investigadora Principal del Proyecto Mujer, Liberalismo y espacio público en perspectiva comparada (HAR2011-26344/HIST) en el que se enmarca este artículo, y especialista en Historia de las Mujeres desde su tesis doctoral hasta hoy, cabe señalar la obra de Rosa $\mathrm{M}^{\mathrm{a}}$ Capel Martínez, entre la que únicamente citaremos aquí su última publicación como editora de un trabajo coral, con resultados de diferentes miembros del proyecto, vid. CAPEL MARTínez, R.: Presencia visibilidad de las mujeres: recuperando historia. Madrid, Abada Editores, 2013. Entre estos trabajos hay uno nuestro en el que precisamente se ha trabajado con documentación del AGMS relativa a mujeres de oficiales "Necesidad que o virtud. La Compañía de Santa Bárbara, primera unidad militar femenina, Gerona, 1808-1809”, pp. 157-220. 
Ocerín a la hora de catalogar los fondos por los apellidos de las esposas- en estos expedientes matrimoniales está esperando un importante yacimiento documental que puede permitir dar con las claves de su grado de autonomía en la toma de decisiones cuando el marido se ausentaba, de su formación y la educación que procuraban como "ángeles del hogar" a sus hijos e hijas e, incluso, su papel en los nuevos espacios públicos del XVIII y en la representación social que llevaba implícito el destino de sus maridos. Sin duda, una historia por recuperar.

Y no solo eso, desde la perspectiva de la historia social de la Edad Moderna, nuestras investigaciones sobre historia militar durante muchos años, consultando expedientes personales y matrimoniales integrados en los primeros, cabe afirmar que hemos ido detectando cómo en el XVIII se fue tejiendo una especie de red familiar estrechamente asociada al vínculo profesional entre militares. De hecho, son recurrentes los casos de hermanas de oficiales que, con sus mismos apellidos, iniciaron los trámites para obtener licencia matrimonial con compañeros de armas de sus familiares; o de viudas de oficiales que contraen segundas nupcias con compañeros de armas de su primer marido.

\subsection{SERIE DE EXPEDIENTE DE PENSIONES, RETIROS Y PAGAS DE TOCA}

Estrechamente vinculadas a la serie de Expedientes Matrimoniales, citaremos para finalizar con la Primera Sección, la Serie de Expedientes de Pensiones, retiros y pagas de toca, para solicitar el derecho a pensión, y las series Pensión de Monte Pio 1 y 2. Las tres tienen relación entre sí, y con la creación del Montepío militar por Carlos III que es su órgano de procedencia.

Pensiones, Retiros y pagas de Toca es un fondo poco trabajado y agrupado como serie documental con nutrida documentación para el estudio del siglo XVIII. Las restricciones, limitaciones y condiciones ya vistas a la hora de contraer matrimonio los militares y expedir las Reales Licencias, eran la base de la instrucción de los Expedientes Matrimoniales y la base documental que, en caso de fallecimiento o desaparición, permitía que la viuda y huérfanos cobrasen una pensión. Estamos ante un fondo compuesto por 2039 expedientes en los que se conserva documentación bautismal, matrimonial y partidas de defunción junto con últimas voluntades o testamentarías y testimonios diversos aportados para reclamar el derecho a pensión, ayudas o subsidios ${ }^{148}$.

Este fondo documental tiene como procedencia el Montepío Militar y la documentación derivada como consecuencia del fallecimiento de los militares, instruida por iniciativa de las viudas o huérfanos para la solicitud de pensiones, con exhaustivas justificaciones de la petición y documentos acreditativos diversos.

De las dos subseries, Pensión de Monte Pio 1 y 2, la primera está formada por 356 legajos y la segunda por 198 legajos, con fechas extremas de 1761 a 1844, que agrupan memoriales de viudas, huérfanos, y -en el caso de huérfanas- no eran ellas quienes elevaban la tramitación sino sus tutores como representantes legales en su nombre.

\footnotetext{
148 Los datos y cifras son los que aparecen en la ya citada Guía del Archivo...
} 


\section{SEGUNDA SECCIÓN. ASUNTOS}

De entre las secciones del AGMS merecen una atención pormenorizada la segunda y tercera, de ahí que durante los años de dirección del AGMS por parte del Coronel Borreguero García se editaran dos inventarios-catálogos sobre estos voluminosos y ricos fondos documentales, que siguen siendo hoy una referencia obligada de partida para el inicio de nuestras investigaciones en historia militar de la Edad Moderna ${ }^{149}$. La procedencia de esta documentación es la Secretaría de Estado y del Despacho de la Guerra y las instituciones que con posterioridad asumieron esas funciones, con un total de 3.769 legajos -según datos tomados de la Guía del Archivo-y fuentes desde el siglo XVI al XX. En el Reglamento de 1898 , estas dos secciones $2^{\mathrm{a}}$ y $3^{\mathrm{a}}$, se organizaron con criterios temáticos a partir de un específico glosario de conceptos, a modo de descriptores, propios del lenguaje de la Administración Militar y que para la $2^{\mathrm{a}}$ se agruparon bajo el genérico y más amplio de "asuntos"

En la sistematización de la segunda sección se estructuraron 16 divisiones agrupadas también temáticamente, lo que queda sintetizado en el siguiente cuadro:

\section{SECCION SEGUNDA}

\begin{tabular}{|c|l|l|c|}
\hline DIVISION & ASUNTO & \multicolumn{1}{|c|}{ DOCUMENTACION } & $\begin{array}{c}\mathrm{N}^{\mathrm{o}} \mathrm{de} \\
\text { legajos }\end{array}$ \\
\hline $1^{\mathrm{a}}$ & Armamento & $\begin{array}{l}\text { Armas blancas y de fuego, ligeras y pesadas, } \\
\text { municiones y explosivos. Compra de armas, } \\
\text { fabricación de armamento (fechas extremas: 1654- } \\
1919)\end{array}$ & 164 \\
\hline $2^{\mathrm{a}}$ & Ascensos & $\begin{array}{l}\text { Ascensos de oficiales en los distintos Cuerpo y Armas } \\
\text { del Ejército. Legislación. (fechas extremas 1713- } \\
1930)\end{array}$ & 91 \\
\hline $3^{\text {a }}$ & Asuntos Generales & $\begin{array}{l}\text { Asuntos que por su temática no se encuadran en el } \\
\text { resto de divisiones de esta sección. Documentación } \\
\text { de temática muy diversa y dispersa, de gran interés. } \\
\text { (fechas extremas 1666-1932) }\end{array}$ & 184 \\
\hline $4^{\text {a }}$ & Campañas & $\begin{array}{l}\text { Fondo que reúne documentación sobre las campañas } \\
\text { en las que intervino el Ejército entre 1509 y 1933 }\end{array}$ & 216 \\
\hline $5^{\text {a }}$ & Contabilidad & $\begin{array}{l}\text { Documentación de carácter económico, libros de caja, } \\
\text { extractos, justificantes de revistas... de diferentes } \\
\text { unidades y cueros del ejército. Fechas extremas 1600 } \\
\text { a 1930 }\end{array}$ & 1563 \\
\hline $6^{\text {a }}$ & Destinos & Legislación y órdenes de destino a partir de 1794 & 110 \\
\hline $7^{\text {a }}$ & Estadísticas & $\begin{array}{l}\text { Desde 1808 contiene datos sobre desaparecidos y } \\
\text { fallecidos en campaña y algunos estados de fuerza de } \\
\text { interés. }\end{array}$ & 34 \\
\hline
\end{tabular}

149 Borreguero García, E.: Catálogo de Documentos. Segunda Sección. Archivo General Militar de Segovia, Madrid, 1986.

150 Herrero Fernández-Quesada, op. cit. (n. 128), p. 354. 


\begin{tabular}{|c|l|l|c|}
\hline $8^{\text {a }}$ & Instrucción & $\begin{array}{l}\text { Documentación relativa a la formación de los militares } \\
\text { y, especialmente a su renovación e institucionalización } \\
\text { a partir del XVIII. Colegios, academias, centros, } \\
\text { textos... Fechas extremas 1701-1930 }\end{array}$ & 557 \\
\hline $9^{\text {a }}$ & Justicia & $\begin{array}{l}\text { Legislación, reformas, Códigos de Justicia Militar.... } \\
1682-1934\end{array}$ & 65 \\
\hline $10^{\text {a }}$ & Organización & $\begin{array}{l}\text { Este concepto es clave para los ejércitos. Organización } \\
\text { y reformas generales del Ejército, Ordenanzas, } \\
\text { reglamentos... Orgánica de las unidades, instituciones } \\
\text { militares y diferentes armas o cuerpos. Fechas } \\
\text { extremas 1666 a 1935 }\end{array}$ & 322 \\
\hline $11^{\text {a }}$ & Reclutamiento & $\begin{array}{l}\text { Reglamentaciones sucesivas referentes al } \\
\text { reclutamiento y alistamientos en los ejércitos, con } \\
\text { expresión de las exenciones, licencias, voluntariado... } \\
\text { Fechas extremas 1686-1930 }\end{array}$ & 57 \\
\hline $12^{\text {a }}$ & Recompensas & $\begin{array}{l}\text { Información y legislación sobre la diversa tipología } \\
\text { de las recompensas o compensaciones por servicios } \\
\text { prestados en los ejércitos (Cruz de San Fernando, San } \\
\text { Hermenegildo...) }\end{array}$ & 187 \\
\hline $13^{\text {a }}$ & Remonta & Sobre la remonta, ganado, sementales... & 26 \\
\hline $14^{\text {a }}$ & Sanidad & $\begin{array}{l}\text { Enfermedades, epidemias, medidas higiénicas, } \\
\text { atención hospitalaria y asistencia facultativa... Desde } \\
1704 \text { a 1932 }\end{array}$ & 117 \\
\hline $15^{\text {a }}$ & Administración & $\begin{array}{l}\text { Fondo relativo a contratos, alquileres, transporte } \\
\text { de las tropas, suministros y abastecimiento de los } \\
\text { ejércitos... Desde 1666 a 1930 }\end{array}$ & 215 \\
\hline $16^{\text {a }}$ & Uniformidad & $\begin{array}{l}\text { Vestuario en general de los ejércitos, equipación, } \\
\text { emblemas y divisas... 1700-1940 }\end{array}$ & 73 \\
\hline
\end{tabular}

De esta síntesis de contenidos reflejada en el cuadro anterior podemos hacernos una idea aproximada sobre la versatilidad temática de esta segunda sección del archivo segoviano, que posibilita la investigación en los aspectos más técnicos y específicos de los ejércitos, singularmente todo lo que se refiere a los medios y materiales para hacer la guerra: el armamento, en sus diferentes variantes, armas blancas, de fuego, portátiles o la artillería como sistema de armas. Asociado a ello, se puede consultar información exhaustiva sobre su fabricación, sus diseños, la evolución tecnológica incorporada a los diferentes procesos de fabricación y no solo de las armas en general, sino de las minas, municiones, bombas, granadas, cohetes, espoletas y todo lo que tiene que ver con la pirotecnia militar.

En principio y dentro de la sección segunda, cabe señalar especialmente la división $8^{a}$ que bajo el genérico de "instrucción", la consulta de su documentación ha hecho posible en las últimas décadas que se hayan renovado las investigaciones sobre la enseñanza militar en la Edad Moderna, la formación de los oficiales de los ejércitos con tesis y trabajos en la mente de todos ${ }^{151}$.

151 En el epígrafe dedicado a historiografía ya aparecen citadas las obras y monografías sobre ello de Capel y Herrero. 
Sin embargo, dentro de la segunda sección, una de las divisiones más feraces y desconocida para el investigador es la $3^{\mathrm{a}}$ que bajo el laxo descriptor de "asuntos generales", sin duda, sorprende en su consulta y análisis documental fundamentalmente por la variopinta temática de sus fondos. Como dato solo citaremos que contiene interesantes documentos de la Guerra de la Independencia tanto impresos como manuscritos ${ }^{152}$, desde el Manifiesto de la Nación Española a la Europa, el manifiesto de declaración de Guerra a Napoleón, como la alocución de Murat en 1808, un nutrido conjunto de Bandos dirigidos a la población y a los ejércitos publicados en diferentes puntos de la geografía peninsular, a los llamados Avisos Públicos, por citar algunos de ellos.

La segunda sección conserva dispersos entre sus numerosos legajos una documentación que, temáticamente, es muy diversa y que incluso en principio puede parecer que no corresponden a un archivo militar. Por razones de espacio solo podemos mencionar algunos ejemplos como la Ejecutoria de la Sacra Rota Romana, prohibiendo que las boticas de los conventos de religiosas de Barcelona despachen medicamentos $(1747)^{153}$; o la documentación relativa a la epidemia de cólera en Mallorca fechada en $1692^{154}$.

Y, abundando en el mismo sentido, cabe destacar la división $14^{\mathrm{a}}$, que bajo la amplia descripción de "enfermedades, epidemias, medidas higiénicas, atención hospitalaria y asistencia facultativa..." abarca como fechas extremas 1704 a 1932. Sin embargo, en ella hay una serie de fondos impresos del siglo XVIII de gran interés para la investigación del protomedicato y los primeros pasos de la cirugía militar en España con información sobre los centros docentes que para la enseñanza de la medicina y la cirugía tienen su arranque en aquella centuria. Unicamente, recogemos aquí algunos de estos impresos como Reales Ordenes expedidas después de la publicación de la nueva Ordenanza de los Colegios de Cirugía del año 1795, que deben considerarse adicionales a ella, impresa en Aranjuez en 1798; la Real Cédula por la que se establece el Protomedicato, dada en Madrid, en la Imprenta Real en 180, el Reglamento para el gobierno del Cuerpo de Cirujía Militar de Exército, impreso en Córdoba en 1809, o un folleto sobre las Termas de Cuntis en Pontevedra. Balnearios de la Virgen $y$ del Castro. ${ }^{155}$

Finalmente, no cabe duda que los interesados por la genealogía y la heráldica, uniformología, así como la vexilología y militaría en general, en esta sección $2^{\mathrm{a}}$, singularmente en la división $16^{\mathrm{a}}$, encuentran legajos de consulta obligada, con interesante documentación iconográfica y descriptiva ${ }^{156}$.

\section{TERCERA SECCIÓN. MATERIAL}

Por otra parte en la también voluminosa Tercera Sección del AGMS reunida bajo el extenso concepto de "material", se agruparon los fondos documentales en seis

\footnotetext{
152 AGMS, Sección 3 ${ }^{a}$, División 3 ${ }^{a}$, leg. 35.

153 AGMS., Sección 2a, División 14, leg. 89.

154 AGMS, Sección 2a, División 14, leg. 15.

155 AGMS, Sección 2 ${ }^{a}$, División 14, leg. 5.

156 JUANOLA.
} 
divisiones, y entre sus legajos cuenta con documentación particularmente interesante para la investigación del periodo moderno. Igual que la segunda sección, la tercera cuenta también con un Catálogo editado por el Coronel Borreguero ${ }^{157}$.

\section{TERCERA SECCIÓN}

\begin{tabular}{|l|l|l|c|}
\hline DIVISION & ASUNTO & \multicolumn{1}{|c|}{ DOCUMENTACION } & N $^{0}$ de LEGAJOS \\
\hline $1^{\circ}$ & Administración Militar & $\begin{array}{l}\text { No interesa para el estudio de } \\
\text { la historia militar moderna } \\
\text { puesto que sus fondos parten } \\
\text { del XIX y continúan en el XX }\end{array}$ & 44 \\
\hline $2^{\text {a }}$ & Material de Artillería & $\begin{array}{l}\text { Cañones, bocas de fuego en } \\
\text { general, fábricas, fundiciones } \\
\text { de artillería, Maestranzas, } \\
\text { Parques y otras instituciones } \\
\text { fabriles del Arma. De 1700 a } \\
1930\end{array}$ & 185 \\
\hline $3^{\text {a }}$ & Material de Ingenieros & $\begin{array}{l}\text { Defensas en general, zonas } \\
\text { polémicas, fortificaciones, } \\
\text { obras defensivas... De 1700 a } \\
1930\end{array}$ & 1044 \\
\hline $4^{\text {a }}$ & Material de Cuerpos & $\begin{array}{l}\text { Legajos del siglo XIX y XX } \\
\text { sobre materiales automóviles, } \\
\text { defensa química... No interesa. }\end{array}$ & \\
\hline $5^{\text {a }}$ & Material de Oficinas & $\begin{array}{l}\text { Adquisición de material desde } \\
1860 . \text { No interesa }\end{array}$ & 2 \\
\hline $6^{\text {a }}$ & Material de Sanidad & Fondos del siglo XIX & 40 \\
\hline
\end{tabular}

En cuanto a la procedencia de estos fondos, además de los generados por las diferentes Comandancias de Ingenieros cuantitativamente dominantes, merece la pena recordar que cuenta con importante presencia la documentación procedente del archivo de artillería y todo lo que tiene que ver con este Cuerpo, de ahí que sea ciertamente valiosa para la investigación en el siglo XVIII.

Dentro de esta sección del AGMS, en especial mencionaremos la división $3^{\text {a }}$, aquella que integra todo lo relativo a las llamadas "zonas polémicas" o puntos histórica y estratégicamente en conflicto o amenazados que han necesitado de una atención preferente en sus sistemas de defensa, fortificaciones, castillos, baluartes, baterías de costa y edificios que -en ocasiones sin ser de origen militar en su fábrica- se reconvirtieron en su uso, adaptándolo para el alojamiento de tropas, unidades o defensas en general. Precisamente por ello, en $3^{\mathrm{a}}, 3^{\mathrm{a}}$, se conserva un importante montante de documentación iconográfica, con planos, mapas, alzados, proyectos de reformas o construcción de acuartelamientos, fábricas o edificios de diverso uso.

157 Borreguero García, E.: Catálogo de documentos. Tercera Sección. Archivo General Militar. Segovia, Madrid, 1988. 
De la misma forma, en material se integraron también legajos que contienen fondos documentales sobre las importantes fábricas militares españolas (ya estatalizadas con Carlos III y dirigidas por los miembros del Cuerpo de Artillería), las Maestranzas, los acuartelamientos, la artillería, lo relativo a la sanidad en los ejércitos (aunque estos últimos fondos trascienden nuestro marco cronológico porque en su mayoría son del XIX), puentes y todo tipo de obras e infraestructuras para la mejora de las comunicaciones. Una documentación, por tanto, que presenta interés para trabajar en múltiples vías de investigación no solo de la historia militar moderna, sino de la ciencia y la tecnología ilustradas, tan vinculadas a las actividades de los oficiales de los Reales Ejércitos.

Las posibilidades temáticas a la hora de realizar investigaciones sobre fuentes primarias de esta naturaleza son más que amplias, poliédricas: estudios sobre la evolución histórica de las intervenciones en edificios señeros del patrimonio español, o trabajos sobre el urbanismo en diferentes ciudades con expresión de la implicación e intervención decisiva en su diseño y planeamiento por parte de los ingenieros militares españoles, por apuntar solo alguna de las investigaciones mas frecuentes sobre estos fondos, conservados en la sección $3^{\mathrm{a}}$, división $3^{\mathrm{a}}$.

Sin embargo, como ya se ha hecho en la Sección $2^{\text {a }}$, no podemos dejar de particularizar algunos documentos de la $3^{\mathrm{a}}$ sección que ilustran lo anterior, como un Reglamento e instrucción para el gobierno de la Maestranza de Orán, firmado por José Patiño en $1736^{158}$, planos y proyectos de obras del castillo de San Sebastián en Cádiz, firmados por Sabatini en $1797^{159}$, o un interesante proyecto para hacer navegable el río Manzanares de 1770 que lleva el sello de la Ilustración en estado puro ${ }^{160}$.

\section{NOVENA SECCIÓN. JUSTICIA}

Se conservan entre sus legajos todos los documentos reunidos sobre "Justicia Militar" ${ }^{161}$ con causas, expedientes gubernativos, administrativos e informativos propios del sistema jurídico militar; así como asuntos procedentes del Consejo Supremo Militar. La sección $9^{\mathrm{a}}$ en su clasificación también sigue un orden alfabético, no existiendo catálogo editado de este fondo. En ella se ofrecen cuatro vías de búsqueda; causas, pleitos, causas sin reos y moros.

Esta importante sección del AGMS ha sido de las más desconocidas, con algunos de sus fondos clasificados y, por tanto, de las menos consultadas hasta las últimas décadas del siglo XX, a pesar del enorme interés de las informaciones que ofrece no solo en la instrucción de los procesos y juicios militares por delitos diversos, sino

\footnotetext{
158 AGMS, Sección 3a, División 2a ${ }^{a}$, leg. 92.

159 AGMS, Sección 3a, División 3a ${ }^{a}$, leg. 93.

160 AGMS, Sección 3 ${ }^{a}$, División 3 ${ }^{a}$, leg. 899.

161 Herrero Fernández-Quesada, M. ${ }^{\mathrm{a}}$ D.: Voz “Justicia Militar”, en Diccionario temático, Artola, M.(dir.): Enciclopedia de Historia de España, Madrid, 1993, vol. IV.
} 
porque además acoge las testamentarías y últimas voluntades de militares al servicio de los Ejércitos ${ }^{162}$.

Ciertamente, los testamentos de los militares recogían sus datos de filiación personal y familiar, pero también los profesionales, con un procedimiento común en el periodo moderno: a su fallecimiento se realizaba un inventario general de todos sus bienes para su tasación por peritos especializados, según su naturaleza, con el fin de tramitar y ejecutar la herencia ${ }^{163}$, o -en caso de no haber descendientes- su venta en pública almoneda, costumbre muy habitual en la sociedad de la época ${ }^{164}$. Así, estas fuentes presentan exhaustivas descripciones de viviendas, muebles, pintura, escultura y otras obras de arte, joyas, bibliotecas, vestuario, bodega... información impagable para la investigación en estudios que en las últimas décadas están siendo muy atendidos por parte de la historiografía, como la cultura material o la vida cotidiana ${ }^{165}$.

Pero sin duda, las causas de la novena sección son de un indudable interés historiográfico. En los ejércitos habitualmente se instruían por delitos o comportamientos dudosos que desde el punto de vista de la institución militar debían clarificarse por si se estuviera ante incumplimientos de la disciplina o los reglamentos en vigor. $\mathrm{Y}$ en estos procesos, son especialmente sustanciosos los testimonios directos y de testigos relativos a causas sobre capitulaciones, intervenciones en campaña, comportamientos irregulares de la tropa o de la oficialidad, delitos de deserción, polémicas rendiciones... De la misma forma, la Justicia Militar también incoaba los procesos de los llamados "juicios contradictorios", en los que se abrían investigaciones por la solicitud o concesión de condecoraciones por acciones en campaña y méritos de guerra. Y, finalmente, de los pleitos que conserva la sección $9^{\text {a }}$ del AGMS nos da una idea aproximativa de su volumen documental, un Catálogo editado únicamente con los instruidos en las Islas Canarias ${ }^{166}$.

Sobre los fondos de la $9^{\mathrm{a}}$ sección, podríamos mencionar amplia y variada documentación pero como hemos hecho con otras secciones anteriores, solo citaremos algunos de los más conocidos por haber sido objeto de investigación por parte de los historiadores. De entre las causas judiciales cabe recordar la instruida por la capitulación de Cartagena de Indias firmada por Gabriel Torres Velasco ${ }^{167}$; o la causa al Marqués de Castelar por la rendición de Madrid ante Napoleón en los altos de Cha-

162 GiL MuÑoz, M.: "Un estudio sobre las mentalidades en el Ejército del XVIII (La actitud ante la muerte a través de las testamentarías de los oficiales en el reinado de Carlos III", Cuadernos de Historia Moderna, 10 (1989-1990), pp. 121-146.

163 Cervera Vera, L.: “La familia y el testamento de Sabatini”, Anales del IEM, 12 (1976), pp. 143-181.

164 Ese fue el caso del Conde de Gazola cuya testamentaría trabajamos para su biografía en el Diccionario biográfico... y citado de la Real Academia de la Historia. La documentación permitió seguir todo el proceso y la tasación y preparación de todos los bienes para su venta en púbica almoneda, pues el Conde de Gazola, murió en Madrid soltero y sin descendencia directa.

165 Herrero Fernández-Quesada: op. cit. (n. 128), pp. 356-357.

166 Borreguero, E.: "Catálogo de pleitos incoados en las Islas Canarias pertenecientes al fondo de pleitos de la Novena Sección del Archivo General Militar de Segovia”, en Morales Padrón, F. (coord.): Coloquio de Historia Canaria-Americana. VIII Congreso Internacional de Historia de América (AEA).2000, pp. 31533199.

167 AGMS, Sección 9a ,leg. T-45 y 46. 
martín el 4 de diciembre de $1808 .{ }^{168}$ En cuanto a las testamentarías, resulta difícil la selección, pero entre ellas cabe incluir aquí la de Don Fernando de Silva Álvarez de Toledo, Duque de Alba dado en la Villa de Piedrahita ${ }^{169}$; la del Virrey del Río de la Plata Pedro Cevallos; la del Ingeniero General Sabatini ${ }^{170}$; la del Conde de Gazola ${ }^{171}$; la del Conde de Lacy...

Finalmente, desde el punto de vista historiográfico merece mención aparte, la existencia de testamentarias de mujeres, aforadas de guerra, y viudas en su mayoría que -como se vio en un epígrafe anterior- ha sido objeto de atención y deseo por parte de otras instituciones en la primera mitad del siglo XX, el Archivo Histórico Nacional y la Real Academia de la Historia.

\section{REALES ÓRDENES Y CIRCULARES}

De igual forma, en el AGMS, el investigador puede acceder a un fondo escasamente divulgado, reunido bajo la denominación de "Reales Ordenes y Circulares", ordenado cronológicamente e integrado por una valiosa y muy variada documentación impresa. Acoge la legislación y normativa legal sobre diferentes asuntos de interés militar, pero también de interés político y general. Entre sus tipos documentales encontramos Reales Decretos, Pragmáticas Sanciones, Reales Cédulas, Legislación Militar, Bandos, Tratados de Paz y Declaraciones de Guerra, Reglamentos, Ordenanzas e impresos varios y muy diversos, en razón de su contenido.

De la consulta de sus fondos seleccionamos una muestra orientativa para posibles investigaciones futuras en historia militar de la edad moderna. Entre sus legajos conviven documentos tan distintos en su tipología, temática y procedencia como la Real pragmática de Felipe V por la que se crea una Junta que entienda todos los negocios pertenecientes a la labor y curso de las Monedas, de 22 de noviembre de $1730^{172}$; la Real Cédula prohibiendo la venta de tabaco de Rapé, dada en Madrid a 6 de junio de $1780^{173}$; la Real Cédula relacionando diferentes oficios honestos, editada en Madrid, en Pedro Marín en 1783 174; o la Pragmática sanción por la que se suprime la moneda de oro llamada "escudito" o "veintén", expedida en Madrid en $17866^{175}$.

De igual forma, en Reales Ordenes y Circulares se reúne documentación de interés relativa a la policía, buen gobierno o el orden público como algunos impresos que reflejan la normativa de principios del siglo XVIII dada en diferentes localidades

168 Herrero Fernández-Quesada, op. cit. (n. 84). En el capítulo final de esta publicación, síntesis de nuestra tesis doctoral, se reflejan los resultados de la investigación sobre las Causa a Castelar por la capitulación de Madrid ante Napoleón.

169 AGMS, Sección 9a leg. S-144.

170 AGMS, Sección 9 ${ }^{a}$, leg. S-2. Sobre el testamento del Ingeniero General, publicó un artículo Antonio Ruiz Hernando, vid. Ruiz Hernando, J. A.: "La testamentaría de Francisco Sabatini”, en Francisco Sabatini, 1721-1797. La arquitectura como metáfora del poder, Madrid, Electa, 1993, pp. 91-114.

171 AGMS, Sección 9 $9^{a}$,leg. G-

172 AGMS, Sección 2a, División 5a ${ }^{a}$, leg. 1517.

173 AGMS, Sección 2a, División 9a ${ }^{a}$, leg. 18.

174 AGMS, Sección 2a ${ }^{a}$ División $3^{a}$, leg. 85.

175 AGMS, Sección 2 $2^{a}$, División 5 ${ }^{a}$, leg. 1517. 
con respecto al alumbrado público, desde una Orden para que los criados pongan farolas a las puertas de las casas de los Ministros, de $1713^{176}$, a los Antecedentes sobre la instalación de alumbrado público en Valencia y relación sobre su coste, de 1771 e, incluso, un curioso boceto de un farol para el alumbrado de Zaragoza con la normativa correspondiente ${ }^{177}$.

Y de la misma forma entreverados entre sus legajos, cabe hacer mención de los impresos -mayoritariamente del siglo XVIII- sobre educación como la Carta del maestro de niños a Don Gabriel Álvarez de Toledo, Cavallero del Orden de Alcántara, y primer Bibliotecario del Rey, impresa en Zaragoza en $1713^{178}$ o el Exercicio público de Física Experimental que tendrá lugar en los Estudios Reales de esta Corte, por D. Juan de la Fuente, asistiéndole D. Antonio Fernández Solano, impreso en Ibarra en 1782.

Para finalizar, reviste una importancia singular la producción editorial de los oficiales que dieron a la imprenta sus propios textos y no solo de materias militares, sino también traducciones de obras científicas europeas tan necesarias y frecuentes en la España Ilustrada. De entre todos ellos, solo cabe recordar que fue especialmente gratificante encontrar un ejemplar, de los pocos que se conservan en razón de la censura del texto desde la propia institución militar, de la deliciosa obra del Capitán y literato José Cadalso El buen militar a la violeta. Lección pósthuma del autor del Tratado de los eruditos, impresa en Sevilla en $1790^{179}$.

\section{TIPOLOGÍA DOCUMENTAL}

Para la descripción de los tipos documentales propios de la institución y administración militar, tomamos como referencia el AGMS al que se dedica este trabajo, y hemos seleccionado únicamente dos de los más representativos.

Los archivos militares custodian la documentación generada por los ejércitos, por militares y sus diferentes instituciones y unidades a lo largo de la Historia. Y junto a unos tipos documentales específicos de la institución como los Reales Despachos que certificaban los ascensos y concesión de empleos a los oficiales y jefes, Memoriales de Unidades, Estados de Fuerza de tropas y ejércitos combatientes, el pie de fuerza de las armas y cuerpos, Ordenanzas y Reglamentos Militares, movimientos y revistas de tropas o los partes de batallas por citar tan solo los más conocidos, hay una tipología documental propiamente militar entre la que destacaremos como instrumentos imprescindibles para la investigación en historia militar de la edad moderna las Hojas de Servicio y un nutrido fondo, como tipo documental de interés histórico pero también iconográfico, los llamados Pasaportes Militares.

176 AGMS, Sección 2a, División 15a leg. 56.

177 AGMS, Sección 2a, División 15 ${ }^{a}$, leg. 56.

178 AGMS, Sección 2a, División 3 ${ }^{a}$, leg. 35.

179 AGMS, Sección 2a, División 8 ${ }^{a}$, leg. 162. 


\subsection{HOJA DE SERVICIOS}

Dentro del Expediente Personal que se abría a todo miembro de los ejércitos, La Hoja de Servicios es el documento más caracterizado y específico en el que se volcaban todos los datos necesarios para reflejar la trayectoria profesional del Militar ${ }^{180}$. Fueron introducidas en el reinado de Felipe V, pero su formato y la obligatoriedad de su cumplimentación ya inexcusablemente, datan de tiempos de Carlos III con la edición y entrada en vigor de las Reales Ordenanzas de 1768, artículo siete, título octavo, tratado tercero. En ellas junto a los datos de filiación personal y aspectos valorativos sobre la idoneidad del militar para el desempeño de su profesión, se registraban cronológicamente todos los destinos desempeñados, los servicios prestados y cualquier vicisitud experimentada por el titular.

En el encabezamiento de las Hojas de Servicio -que evolucionaron estética y formalmente con la incorporación de emblemas, escudos o heráldica y su posterior desaparición- junto al nombre y dos apellidos del militar encontramos el emblema o la referencia escrita del arma o cuerpo al que pertenecían. A continuación, en un formato reglado, a modo de cuadro, siempre en columna y por orden figuraban la fecha de ingreso en los ejércitos y las de los sucesivos ascensos y cambios de destino, con expresión del número de años, meses y días que permaneció en cada uno de ellos hasta lo que se conoce como la fecha de cierre de esa Hoja de Servicios. Como la vida profesional del militar continuaba, a partir de la anterior se abrían otras, sucesivas Hojas de Servicio, con diferente fecha de rúbrica y cierre que, sumadas y sin dejar ningún vacío cronológico, totalizaban la trayectoria militar hasta el retiro o la muerte. En este sentido, lo habitual es que al investigar sobre un expediente personal de un militar determinado, siempre encontremos mas de una y de dos Hojas de Servicio.

En el siglo XVIII, en el reverso de las Hojas de Servicio, se hacía constar siempre la Calidad (noble por ejemplo), el estado civil, la edad, la patria, la disposición personal, la salud (que no siempre era buena), la conducta, el valor, la capacidad, la aplicación, la teórica, la práctica y un último concepto formulado como "es a propósito", donde sus jefes inmediatos -que firmaban el documento- hacían constar los destinos o comisiones más apropiados para su perfil profesional. En otros apartados menos telegráficos, de más amplio desarrollo, figuraban los "Ejércitos y Cuerpos donde había servido", comisiones desempeñadas y hechos de armas en los que intervino, con impagables descripciones al detalle de su participación en ellos.

En suma, la Hoja de Servicios además de ser el tipo documental más representativo de los archivos militares, sin duda constituye una inestimable fuente, y el AGMS es el centro que cuenta con mayor número de ellas, integradas en los Expedientes Personales de los profesionales. Esto no impide que encontremos esta tipología documental en otros archivos como el General de Simancas donde se conservan Hojas de Servicio de Militares del XVIII, pero como sueltos, sin expediente.

180 Herrero Fernández-Quesada, M. a D.: Voz "Justicia Militar", en Diccionario temático, Artola, M. (dir.): Enciclopedia de Historia de España, Madrid, 1991, vol. IV. 


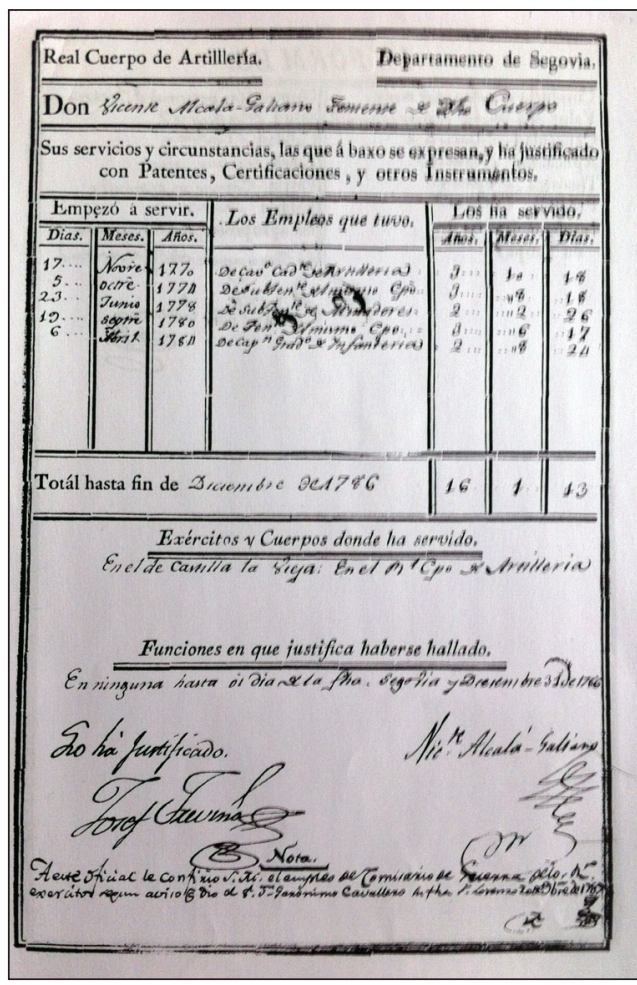

Fig. 1. Hoja de Servicios de Vicente Alcalá Galiano. Anverso.

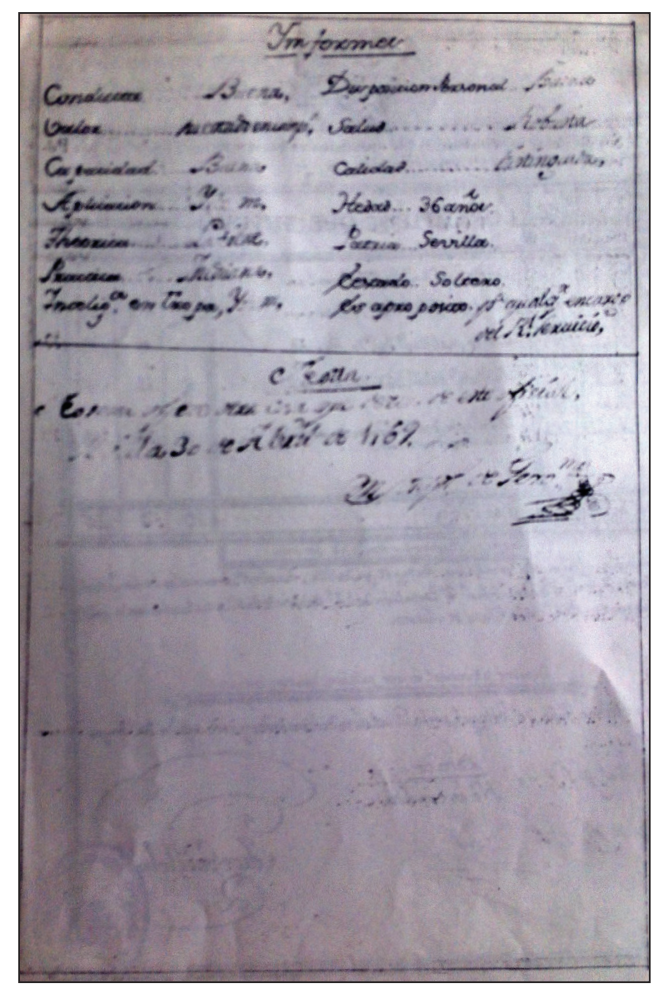

Fig. 2. Hoja de Servicios de Vicente Alcalá Galiano.Reverso.

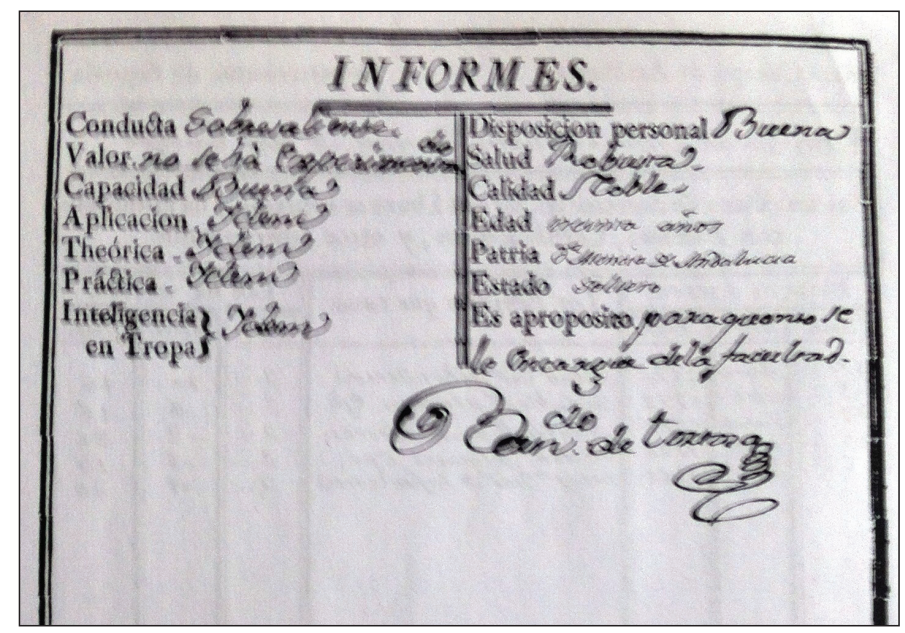

Fig. 3. Informes en la hoja de servicios. 


\subsection{PASAPORTES MILITARES O PASAPORTES HERÁLDICOS}

En los años ochenta, la dirección del AGMS reunió una colección de Pasaportes Militares que sin haber sido en origen ninguna serie ni subserie, ha emergido de forma natural con el paso del tiempo como fondo documental con entidad propia y que, finalmente, se ha editado como Catálogo por el Coronel Borreguero ${ }^{181}$.

En la consulta de los investigadores a lo largo del siglo XX de los expedientes personales de los militares, se encontraron con este tipo documental de forma recurrente, puesto que no solo con este documento se facilitaba el desplazamiento autorizado de los oficiales. Con este formato documental, con el mismo encabezamiento e idéntica incorporación de la heráldica de la autoridad militar que lo expedía, los Pasaportes Militares eran acreditativos de licencias diversas, concesiones de empleos o certificaciones profesionales varias. De hecho, los pasaportes presentan una casuística en su empleo muy amplia entre la que merece la pena poner de manifiesto aquí para ilustrarlo, el expedido en Valencia a 6 de marzo de 1789 por Manuel Martínez de Irujo quien tras reseñar uno tras otro todos sus cargos, utilizó este formato documental para certificar que con su licencia y aprobación, y la de su mujer, había mediado "contrato de esponsales entre el Sr. D. Antonio Balaguer, Capitán de Quarto Batallón del Real Cuerpo de Artillería y mi hija Doña Narzisa Martínez de Irujo, Tacón y Gamir..." 182.

Desde el punto de vista iconográfico en el encabezamiento se abren con grabados -algunos de ellos espectaculares- alegóricos, con emblemas y símbolos militares, seguidos del nombre y apellidos, empleos, títulos, cargos y honores del dador, siempre compuestos. En la parte central del pasaporte se incluía el texto que acreditaba el salvoconducto para viajar, la licencia, el empleo o el honor, con expresión del destino y fechas, y con fórmulas textuales comunes y casi clónicas para la misma época histórica. Y, en el plano inferior de estos documentos, aparece la rúbrica de la autoridad militar y siempre el escudo heráldico, de ahí que sean citados indistintamente como Pasaportes Militares o Heráldicos.

Precisamente en sus frecuentes visitas al AGMS, fue Dalmiro de la Válgoma y Díaz Varela, Académico Bibliotecario de la Real Academia de la Historia el primero que los puso en valor en sus investigaciones, publicando un trabajo sobre esta tipología documental de tan frecuente presencia en los expedientes personales de los militares españoles ${ }^{183}$. Con posterioridad y ante el volumen de Pasaportes Heráldicos que se iba reuniendo, el Servicio Histórico Militar, editó la obra Blasones Militares ${ }^{184}$.

El interés de este tipo documental, trasciende lo meramente iconográfico para ser una fuente directa de contenido histórico importante, especialmente para conocer o ratificar datos biográficos o profesionales de la trayectoria de militares de diferente rango y protagonismo en la historia de España. Entre ellos, tan solo citaremos algunos de los mas espectaculares icónicamente o de los mas significados por la importancia del personaje: José Carrillo de Albornoz, Duque de Montemar; Zenón de Somodevilla, Marqués de la Ensenada; José Antonio Caballero, Secretario de Estado

\footnotetext{
181 Borreguero García, E.: Colección de Pasaportes Heráldicos, Madrid, Hidalguía, 1990-1994, 2 tomos.

182 Lo hemos consultado entre los seleccionados en el Catálogo.

183 VÁlgoma y Díaz Varela, D.: Una colección de pasaportes heráldicos, Madrid, Hidalguía, 1969.

184 Blasones Militares, Madrid, SHM, 1987, 2 volúmenes.
} 
y del Despacho Universal de Gracia y Justicia de España e Indias; Santiago Liniers, Gabriel Císcar y Císcar; Martín García Loygorry, Francisco Javier Castaños, Pablo Morillo o el propio Rey Fernando VII.

En este artículo, planteado como un instrumento aplicado a la investigación en historia militar de la edad moderna, no podemos ni aproximarnos al potencial documental de los archivos militares españoles, ni siquiera al del Decano de todos ellos, el AGMS. Pero si porque en este artículo hubiéramos podido reflejar una mínima parte y la emoción vivida en su consulta, se abrieran apetitos investigadores, habríamos superado nuestras expectativas a la hora de abordarlo únicamente desde la experiencia personal y profesional de años trabajando en Historia Militar.

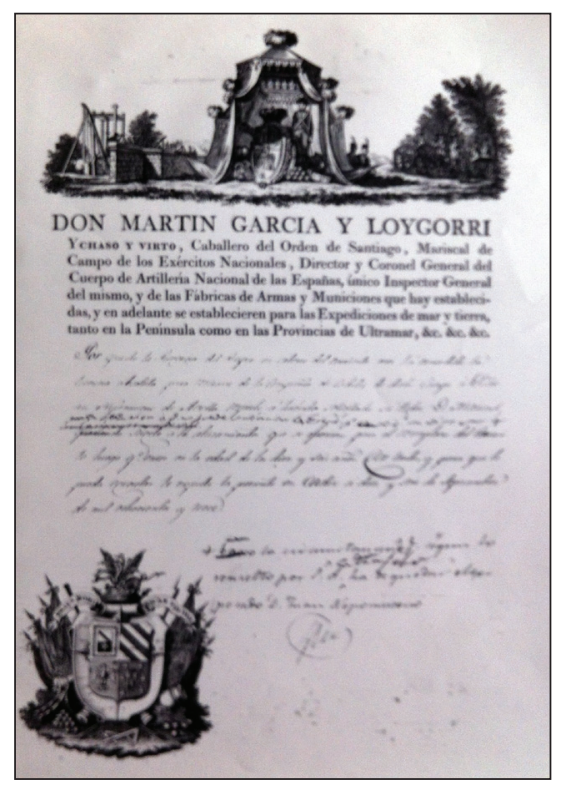

Fig. 4. Pasaporte militar de García y Loygorri.

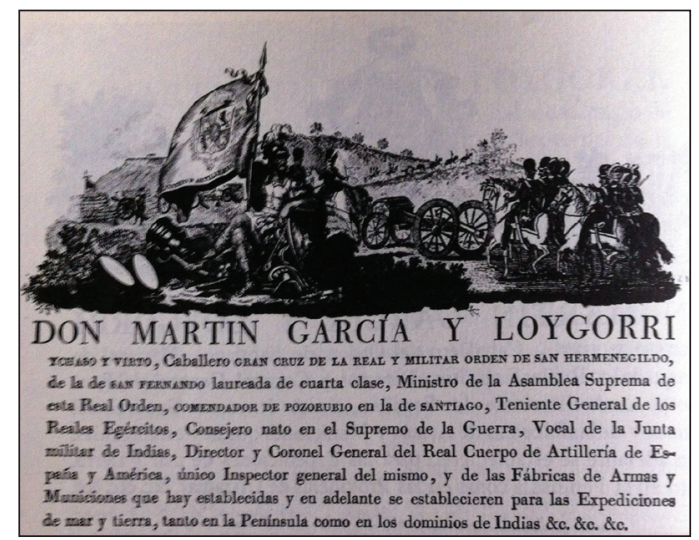

Fig. 5. Encabezamiento pasaporte heráldico de García y Loygorri. 


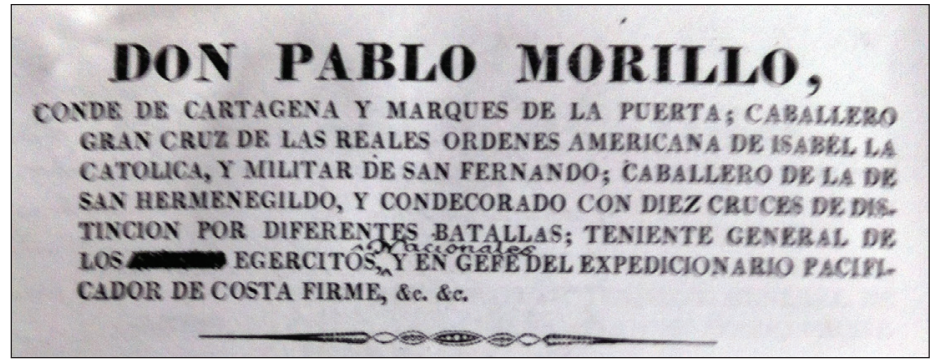

Fig. 6. Encabezamiento pasaporte militar Pablo Morillo.

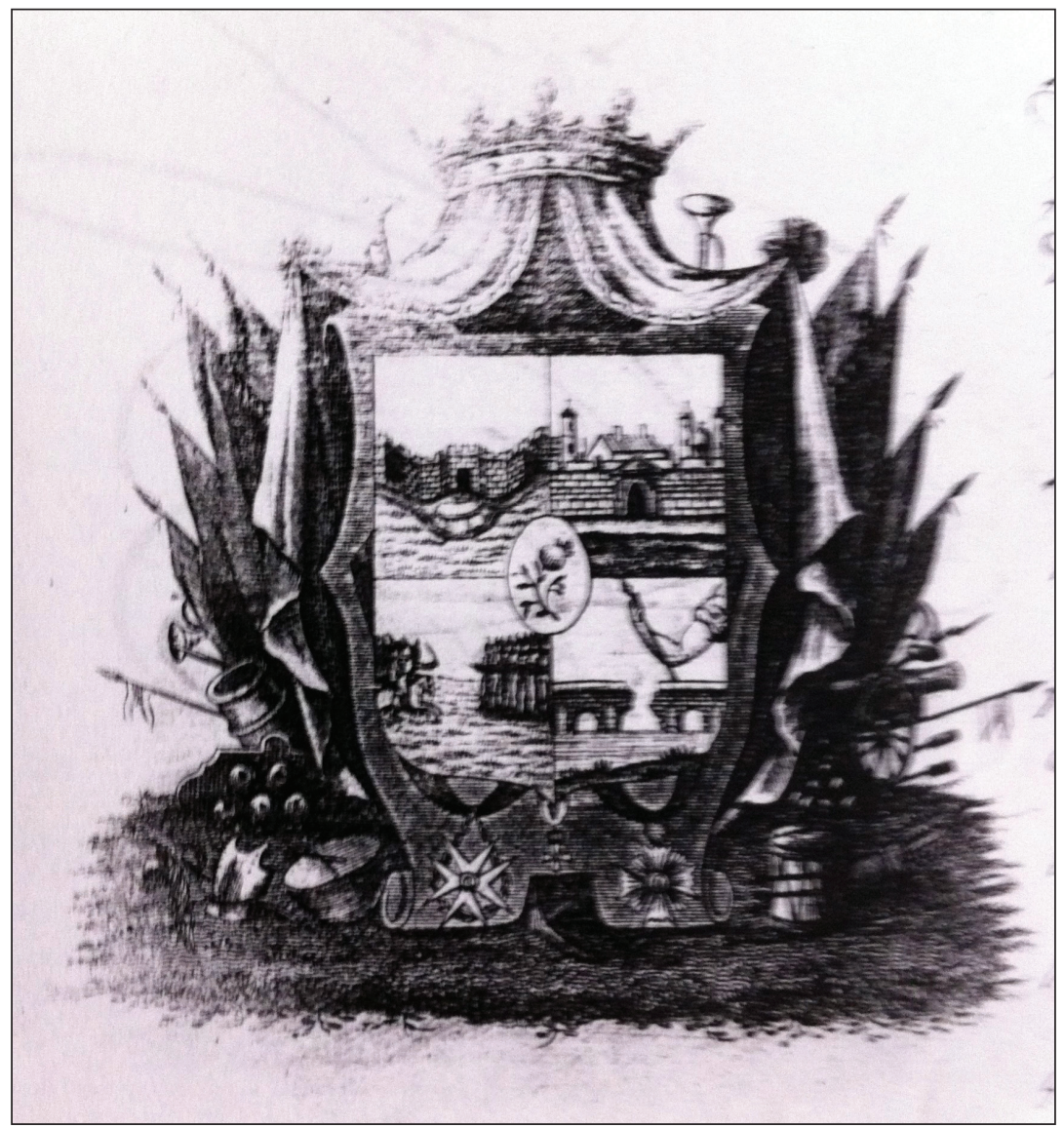

Fig. 7. Heráldica pasaporte militar Pablo Morillo. 